\title{
Percepción del cuidado de enfermería por indígenas Embera
}

\author{
Perception of nursing care by Embera Indigenous people \\ Percepção dos cuidados de enfermagem por indígenas Embera \\ Liliana Orozco-Castillo* \\ Lucero López-Díaz**
}

\begin{abstract}
Autor de correspondencia
* $\triangle$ Enfermera. Magister en Enfermería. Doctora en Enfermería. Docente programa de Enfermería. Universidad de Caldas. Correo: liliana.orozco@ ucaldas.edu.co. Orcid: https://orcid.org/0000-00028686-6168. Manizales, Colombia.

** Enfermera. Magister en Enfermería. Doctora en Enfermería. Docente. Universidad Nacional. Correo: allopezdi@unal.edu.co. Orcid: https://orcid. org/0000-0002-2157-763. Bogotá, Colombia
\end{abstract}

\begin{abstract}
Resumen
Objetivo: Interpretar la percepción del indígena Embera Chami frente a la competencia cultural de la enfermera de salud pública. Materiales y métodos: Etnografía interpretativa con observación participante y entrevistas etnográficas. Participaron siete colaboradores generales y once indígenas receptores de cuidado. El análisis adoptó la propuesta de Leininger con apoyo del Atlas ti y Excel. Emergieron dos categorías, cada una sustentada con dos subcategorías. Resultados: Al observar los Indígenas satisfechos y comprometidos con la enfermera y con la Institución prestadora de servicios de salud intercultural, permitió percibir una actitud positiva respecto del cuidado recibido de la enfermera, siempre en conjunción con la política intercultural y el saber del indígena de tal forma que sea reconocido y considerado. Conclusión: Los indígenas sienten satisfacción y compromiso al poner en práctica las recomendaciones ofrecidas por la enfermera, especialmente cuando el cuidado de la profesional se realiza de manera culturalmente competente teniendo siempre en cuenta su contexto. Pese a que los aspectos con los que el cuidado culturalmente competente puede influir de manera positiva en la salud de los indígenas, los asuntos relacionados con la alimentación balanceada son difíciles de cumplir por este grupo poblacional.
\end{abstract}

Palabras clave: Competencia cultural, enfermera, salud pública, grupos poblacionales
Este es un artículo bajo la licencia CC BY

(https://creativecommons.org/

licenses $/$ by $/ 4.0 /)$ (c) (1)

\begin{abstract}
Objective: Interpret the perception of the Indigenous Embera Chami towards cultural competence of public health nurses. Materials and methods: Interpretative ethnography with participant observation and ethnographic interviews. Seven general collaborators and eleven Emebra Indigenous care recipients participated. The analysis adopted the Leininger proposal supported by Atlas ti and Excel. Two categories emerged, each one supported with two subcategories. Results: Observing satisfied and compromised Indigenous Embera with the nurse and with the institution providing intercultural health care, allowed a positive reception regarding care received by the nurse, always in conjunction with the intercultural policy and the Indigenous knowledge in a manner that it is recognized and considered. Conclusions: Embera Indigenous feel satisfied and compromised when putting in practice the recommendations offered by the nurse, especially when the
\end{abstract}


professional care performed is culturally competent, always considering their context. Although the aspects in which culturally competent care can influence in a positive manner in the health of the Embera indigenous, aspects relating to a balanced diet are difficult to accomplish in this population group.

Key words: Cultural competence, nurse, public health, population groups.
1794-9831

E-ISSN 2322-7028

Vol. 16 No. 2

May - Ago 2019

Cúcuta, Colombia

\section{Resumo}

Objetivo: Interpretar a percepção dos indígenas Embera Chami frente à competência cultural do enfermeiro de saúde pública Metodologia: Etnografia interpretativa com observação participante e entrevistas etnográficas. Sete colaboradores gerais e onze beneficiários de cuidados indígenas participaram. A análise seguiu a proposta de Leininger com o apoio do Atlas ti e do Excel. Duas categorias emergiram, cada uma apoiada com duas subcategorias. Resultados: Os indígenas, satisfeitos e comprometidos com o enfermeiro ea Instituição prestadora de serviços interculturais de saúde, mostram uma percepção positiva do cuidado recebido da enfermeira e da política intercultural onde o conhecimento dos indígenas é reconhecido e considerado. Conclusão: Os indígenas sentem satisfação e compromisso em traduzir as recomendações oferecidas pelo enfermeiro, principalmente quando o cuidado do profissional é feito de forma culturalmente competente, envolvendo o contexto dos indígenas. Apesar dos aspectos com os quais o cuidado culturalmente competente pode influenciar positivamente a saúde dos povos indígenas, questões relacionadas à dieta balanceada são difíceis de serem encontradas para esse grupo populacional

Palavras-chave: Competência cultural, enfermeira, saúde pública, grupos populacionais

\section{Introducción}

Aceptar el concepto de cultura como el conjunto de "valores, creencias, normas y formas de vida practicados, que fueron aprendidos, compartidos y transmitidos por los individuos y los grupos que generan pensamientos, decisiones y acciones de una manera estandarizada" (1) permite reconocer que dicha concepción sobre cultura marca de manera consciente o inconsciente las prácticas de los grupos poblacionales.

La competencia cultural se presenta como un proceso amplio que debe ser adoptado por los sistemas, las instituciones, las políticas y, sobre todo, por los profesionales, quienes han de desarrollar determinada conciencia, conocimientos, actitudes y habilidades para ofrecer sus servicios (1-3). Dichas acciones deben tener en cuenta de manera prioritaria la cultura a la cual se ofrece la atención o el cuidado de la enfermería, proporcionando respuestas efectivas y eficaces a las necesidades del cuidado cultural (4-7). Además hay que mejorar el empoderamiento de los indígenas a partir de la satisfacción que perciban mediante la prestación de los servicios de salud $(8,9)$.

Por otra parte, el proceso de competencia cultural con poblaciones indígenas va más allá de los principios que estipula, ya que además de acortar diferencias en salud y disminuir desigualdades en este sentido, pretende reducir la distancia cultural entre las formas institucionalizadas (y hegemónicas) de atención y las mismas poblaciones indígenas, con el propósito de mejorar el empoderamiento de estas comunidades y así aumentar la satisfacción con la prestación de los servicios de salud (10).

Es por eso que, estudios sobre la medición del nivel de competencia cultural, coinciden en advertir las limitaciones en los cuestionarios utilizados, al basarse únicamente en el profesional $(4,11,12)$, conservando vacíos en el conocimiento de la competencia cultural $(4,5)$ lo cual obliga a buscar elementos que permitan prever si el receptor de cuidado siente que se le cuida de una manera apropiada $(4,13)$.

Debe señalarse que la escasa investigación generada desde la perspectiva del receptor del cuidado, relacionada con el cuidado culturalmente competente, se ha generado desde la investigación cualitativa y se ha enfocado en ambientes hospitalarios $(14,15)$. Por tanto, este estudio pone de manifiesto la importancia de interpretar en el contexto colombiano cómo es la percepción del indígena frente al cuidado recibido por la enfermera de salud pública.

Del mismo modo, hay que subrayar que la competencia cultural ofrecida a las poblaciones indígenas es importante, en virtud de que deben afrontar la pobreza, el aislamiento y la poca atención sanitaria (10); factores que inciden en su salud ya que, además de 
ISSN-PRINT

1794-9831

E-ISSN 2322-7028

Vol. 16 No. 2

May - Ago 2019

Cúcuta, Colombia afectarlos con diversas enfermedades, también inciden en sus creencias, estilos de vida, cosmovisión y prácticas de cuidado, que son usualmente diferentes a las prácticas habituales de sus comunidades $(8,16)$.

En Colombia los indígenas representan cerca del $3,3 \%$ de la población, organizados en 84 etnias reconocidas, siendo la comunidad Embera una de las más representativas. Este grupo habita, entre otros, en el departamento de Caldas donde suman aproximadamente 63.327 personas y están localizados en 10 municipios, configurando el $4,3 \%$ del total de la población del departamento (17).

El pueblo Embera de Caldas se encuentra organizado en 15 cabildos agremiados en la Asociación de Cabildos Indígenas de Caldas -ACICAL- y en el Consejo Regional Indígena de Caldas -CRIDEC-- Dichos entes son los encargados de tomar las decisiones comunitarias que inquietan a los indígenas. En la actualidad, cuentan con parteras, médicos tradicionales, sobanderos y curanderos afiliados a la Asociación de Médicos Tradicionales del Occidente de Caldas -ASOMETROC-. Entre las costumbres vigentes están: los tratamientos con plantas, las mingas, la danza y las artesanías. En cuanto a su forma y preservación de costumbres, han luchado y considerado como uno de sus mayores retos prevenir la pérdida de la lengua Embera y el aumento del mestizaje (18).

\section{Objetivo}

\section{Objetivo general}

Interpretar la percepción del indígena Embera Chami frente al cuidado que recibe de la enfermera de salud pública.

\section{Materiales y métodos}

Se empleó la Etnografía interpretativa $(19,20)$ basada en descripciones densas del comportamiento humano; en este sentido se descubre, conjetura y evalúan dichos significados, para obtener conclusiones explicatorias (21). Se utilizó un muestreo intencional $(21,22)$ con indígenas que recibieran cuidados de enfermería en los controles de crecimiento y desarrollo, hipertensión arterial y planificación familiar en una institución de primer nivel de atención, con lineamientos interculturales y que aceptaron participar en el estudio. Se encontraron dos tipos de colaboradores. Los generales, conformados por siete líderes, a quienes se les realizó entrevistas et- nográficas sobre las generalidades de la cultura Embera; sus informaciones permitieron entender el contexto y el acercamiento a los colaboradores clave, seleccionados bajo criterios de inclusión y exclusión. Se prefirieron a quienes accedieron a hablar con generosidad

De modo similar, a los colaboradores clave las enfermeras los observaron en las consultas; estas observaciones fueron plasmadas en diarios de campo y fotografías; seguidamente, al salir de la consulta se les realizó entre una y tres entrevistas etnográficas, así como en los hogares de los indígenas, ahondando en la percepción sobre la atención ofrecida por la enfermera. Inicialmente se construyó un cuestionario preliminar, cuyo orden y contenido se fue modificando de acuerdo al proceso de cada entrevista. La investigación se desarrolló en 24 meses: 5 fueron de Inserción de campo y 19 de trabajo de campo y análisis de información. Este método nos permitió asistir, observar, grabar y participar en controles, tanto en la zona urbana como en la rural.

Igualmente, los datos obtenidos fueron transcritos textualmente y junto con las fotografías seleccionadas se analizaron de manera sistemática, mediante la organización, reducción, combinación, unificación y disgregación de las citas. El análisis de datos se efectuó con la propuesta de Leininger (1) ayudado con los softwares ATLAS.ti y Excel. La reflexividad fue una constante en todo el proceso investigativo.

Por otra parte, se utilizaron los seis criterios propuestos por Leininger que están relacionados con pautas para demostrar la validez y confiabilidad en la investigación cualitativa: credibilidad, confirmabilidad, significado en contexto, patrones recurrentes, saturación y transferibilidad (1). También se usó la herramienta de análisis cualitativo CASPe (23).

Por último, es importante precisar que esta investigación estuvo enmarcada en la resolución 8430 . Se utilizó y firmó el consentimiento informado y escrito por parte de los colaboradores clave. Respecto, a los colaboradores generales el consentimiento informado no se formuló por escrito. Se emplearon seudónimos y los datos fueron manejados de manera confidencial. Los momentos de angustia en la investigadora fueron socializados y resueltos con los pares académicos. Este proyecto de investigación obtuvo el aval del Comité de Ética de la Facultad de Enfermería de la Universidad Nacional, la Alcaldía Municipal de 
Riosucio y la Asociación de Cabildos Indígenas de Caldas "ACICAL".

\section{Resultados}

La percepción de los Embera Chami frente al cuidado cultualmente competente realizado por la enfermera de Salud Pública se condensa en dos categorías, cada una sustentada en dos subcategorías respectivamente.

\section{Categoría 1: Como Embera estoy contento con las enfermeras y la Institución prestadora de servicios de salud (IPS) intercultural, aunque en ocasiones me molesta esperar.}

Expresa la percepción de satisfacción de los indígenas frente al cuidado recibido de las enfermeras de salud pública. Con frecuencia, los indígenas explican su agrado al comparar la atención recibida en la IPS intercultural frente a las experiencias pasadas; siendo en muchos casos negativas, producto del servicio en otra institución de salud sin lineamientos interculturales, donde no se les brindó ningún tipo de atención basada en el respeto, la cortesía, el tono de voz sereno y la atención oportuna (según versión de los pacientes). De todos modos, cuando el tiempo de espera para ser atendidos es mayor al estipulado, los indígenas muestran su descontento y molestia, lo que les recuerda su experiencia al ser atendidos en otras IPS.

\section{Subcategoría 1.1: Como Embera estoy contento con la enfermera y con la IPS intercultural, la otra no me gustaba}

Los Embera se sienten satisfechos con el cuidado recibido de las enfermeras de salud pública. Dicho sentir se vincula principalmente con la organización de la IPS, la cual brinda, entre otras cosas: la consecución de citas de manera rápida, el acercamiento de los servicios de atención a algunas comunidades indígenas, el tratamiento respetuoso y la combinación de conocimientos tradicionales con occidentales.

Con relación a la complementariedad en los procesos de atención tradicional y occidental, los indígenas acceden a ambos tratamientos, pues dentro de sus creencias consideran que los dos saberes tienen cabida y aceptación de manera natural.

Al mismo tiempo, los indígenas Embera Chamí se sienten bien atendidos en los controles por las enfermeras de salud pública. La justificación verbal no es detallada en relación con el significado de sentirse bien atendidos, sin embargo, manifiestan que las enfermeras de salud pública les explican con claridad todo lo relacionado con su salud y las acciones o cui-

dados que deben realizar. Hablan de su formalidad, su
cordialidad y su atención respetuosa
"La enfermera es muy formal, le dice y le ex-
$\quad$ plica a uno bien las cosas, cómo debe tomarse
uno los medicamentos, para mi está bien así”.
(Indigena PG, 13-3:23)
La explicación y las respuestas de las enfermeras ante
las dudas suscitadas por el indígena también son ex-
presadas como actos de cuidado adecuado.
Otro factor con el que los indígenas se sienten bien
atendidos se relaciona con la formalidad y el respeto
en el cuidado que les brindan las enfermeras de salud
pública. Esta situación se expresa a través de: el salu-
do atento y amigable, el acercamiento físico educado,
la indagación holística y profunda sobre el estado de
salud percibida por los indígenas y lo que puede estar
afectando su tranquilidad.
$\quad$ "Atienden súper bien, la atención y como la
$\quad$ forma de ser de todos, lo reciben a uno con un
$\quad$ gesto amable, vea este momento: yo salí como
liviana con todo lo que dije. Sali muy bien, aquí
la atención es sobrada. Me siento súper bien”.
(Indigena CR, 13-13:18)
De igual forma, para los indígenas los gestos ami-
gables, las sonrisas, el contacto físico educado, la
atención a sus comentarios, las palabras amables y
la empatía de las enfermeras facilitan la labor. Con
estas actitudes son valoradas como buenas o malas
profesionales al momento de evaluar la atención y el
cuidado. Inclusive, si la enfermera durante la cita no
del indígena de asistir o no al control.

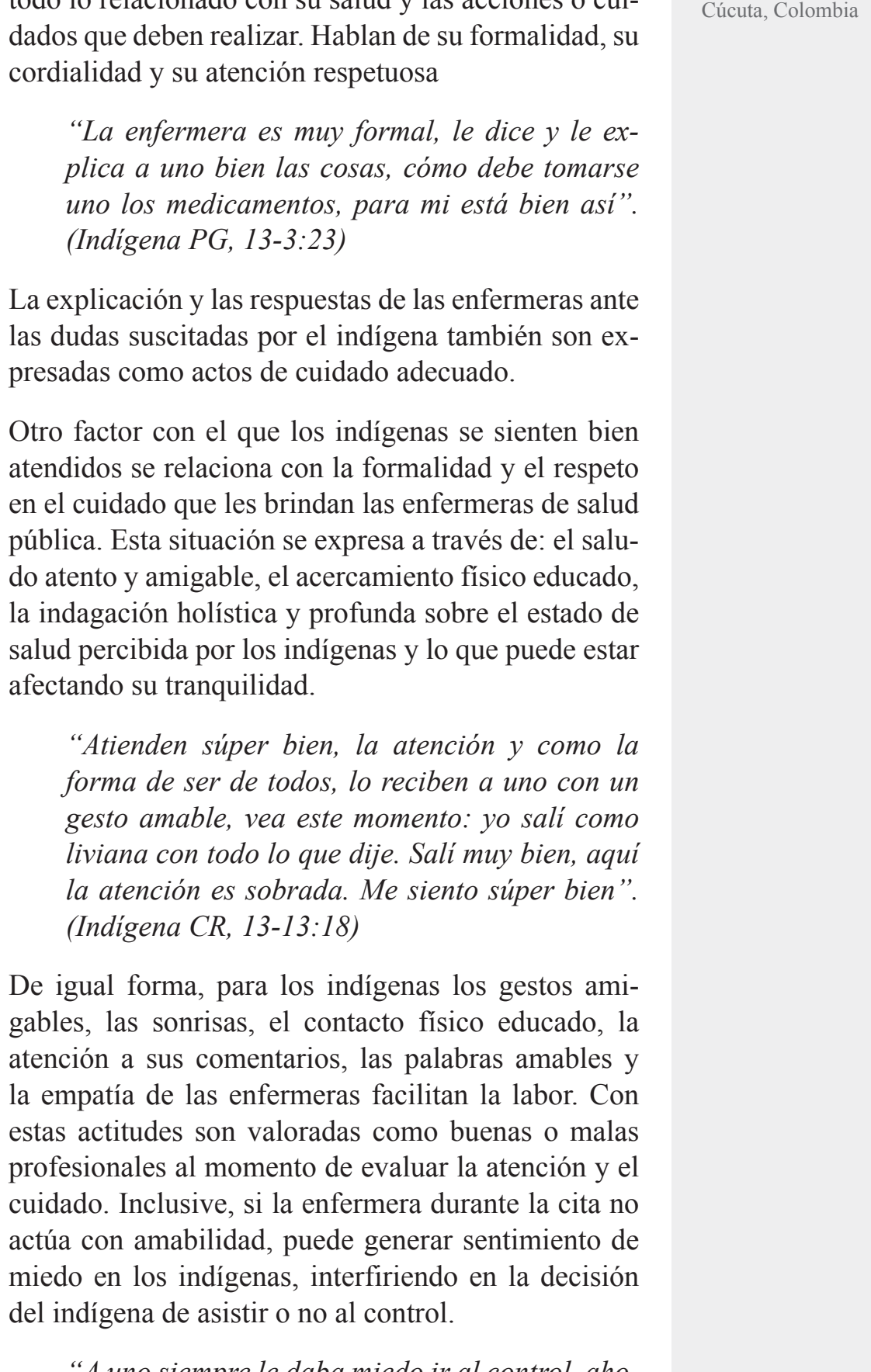

"La enfermera es muy formal, le dice y le ex-
plica a uno bien las cosas, cómo debe tomarse
uno los medicamentos, para mi está bien así.
(Indígena PG, 13-3:23)
xplicación y las respuestas de las enfermeras ante
dudas suscitadas por el indígena también son ex-
adas como actos de cuidado adecuado.
factor con el que los indígenas se sienten bien
didos se relaciona con la formalidad y el respeto
cuidado que les brindan las enfermeras de salud
ica. Esta situación se expresa a través de: el salu-
danto y amigable, el acercamiento físico educado,
d percibida por los indígenas y lo que puede estar
"Atienden súper bien, la atención y como la
forma de ser de todos, lo reciben a uno con un
gesto amable, vea este momento: yo salí como
liviana con todo lo que dije. Sali muy bien, aquí
la atención es sobrada. Me siento súper bien”.
(Indígena CR, 13-13:18)
gual forma, para los indígenas los gestos ami-
es, las sonrisas, el contacto físico educado, la
ción a sus comentarios, las palabras amables y
mpatía de las enfermeras facilitan la labor. Con
actitudes son valoradas como buenas o malas
adionales al momento de evaluar la atención y el
ado. Inclusive, si la enfermera durante la cita no
con amabilidad, puede generar sentimiento de
ando su tranquilidad.

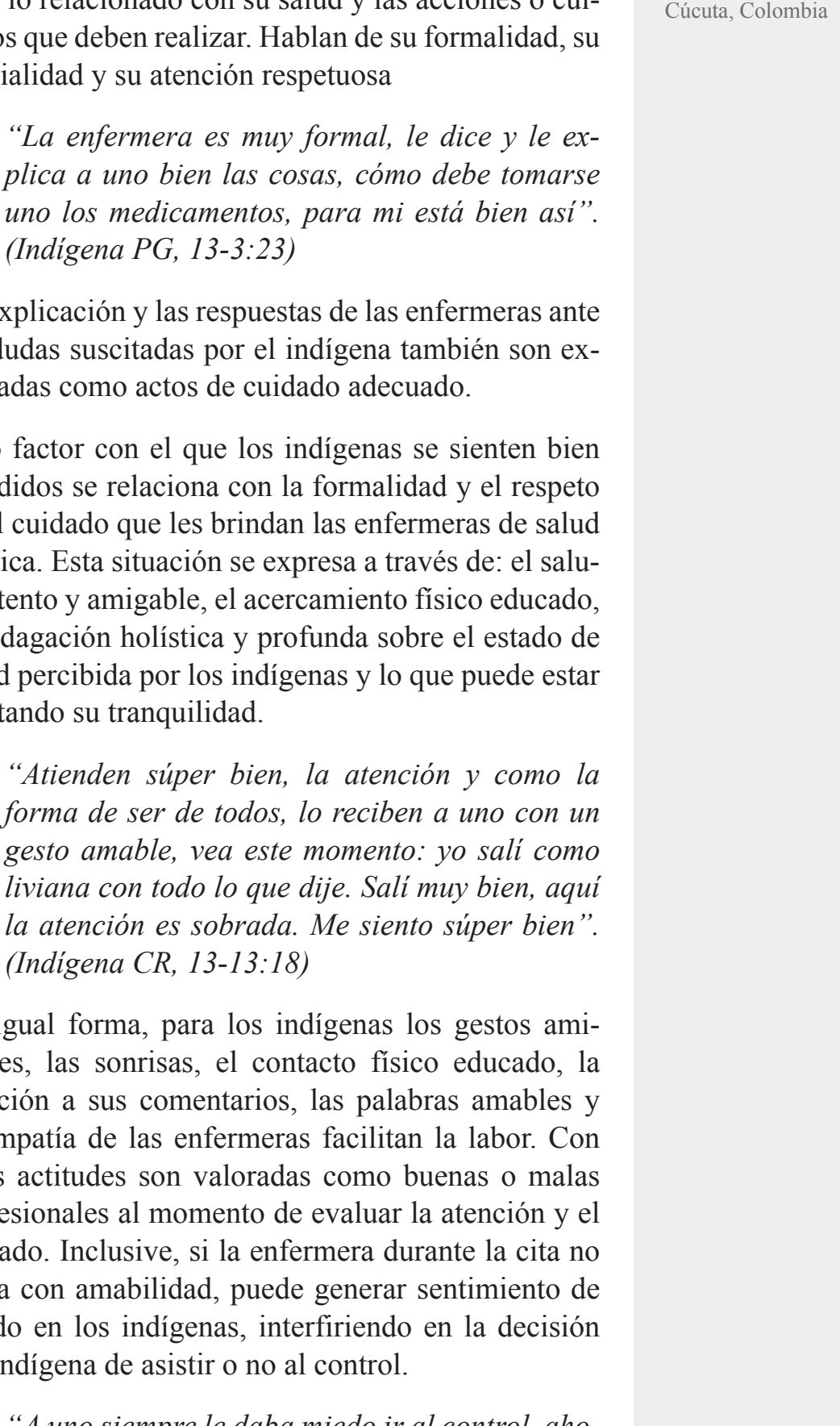

"La enfermera es muy formal, le dice y le ex-
plica a uno bien las cosas, cómo debe tomarse
uno los medicamentos, para mi está bien así.
(Indígena PG, 13-3:23)
xplicación y las respuestas de las enfermeras ante
dudas suscitadas por el indígena también son ex-
adas como actos de cuidado adecuado.
factor con el que los indígenas se sienten bien
didos se relaciona con la formalidad y el respeto
cuidado que les brindan las enfermeras de salud
ica. Esta situación se expresa a través de: el salu-
danto y amigable, el acercamiento físico educado,
d percibida por los indígenas y lo que puede estar
"Atienden súper bien, la atención y como la
forma de ser de todos, lo reciben a uno con un
gesto amable, vea este momento: yo salí como
liviana con todo lo que dije. Sali muy bien, aquí
la atención es sobrada. Me siento súper bien”.
(Indígena CR, 13-13:18)
gual forma, para los indígenas los gestos ami-
es, las sonrisas, el contacto físico educado, la
ción a sus comentarios, las palabras amables y
mpatía de las enfermeras facilitan la labor. Con
actitudes son valoradas como buenas o malas
adionales al momento de evaluar la atención y el
ado. Inclusive, si la enfermera durante la cita no
con amabilidad, puede generar sentimiento de
ando su tranquilidad.

"La enfermera es muy formal, le dice y le ex-
plica a uno bien las cosas, cómo debe tomarse
uno los medicamentos, para mi está bien así.
(Indígena PG, 13-3:23)
xplicación y las respuestas de las enfermeras ante
dudas suscitadas por el indígena también son ex-
adas como actos de cuidado adecuado.
factor con el que los indígenas se sienten bien
didos se relaciona con la formalidad y el respeto
cuidado que les brindan las enfermeras de salud
ica. Esta situación se expresa a través de: el salu-
danto y amigable, el acercamiento físico educado,
d percibida por los indígenas y lo que puede estar
"Atienden súper bien, la atención y como la
forma de ser de todos, lo reciben a uno con un
gesto amable, vea este momento: yo salí como
liviana con todo lo que dije. Sali muy bien, aquí
la atención es sobrada. Me siento súper bien”.
(Indígena CR, 13-13:18)
gual forma, para los indígenas los gestos ami-
es, las sonrisas, el contacto físico educado, la
ción a sus comentarios, las palabras amables y
mpatía de las enfermeras facilitan la labor. Con
actitudes son valoradas como buenas o malas
adionales al momento de evaluar la atención y el
ado. Inclusive, si la enfermera durante la cita no
con amabilidad, puede generar sentimiento de
ando su tranquilidad.

dados que deben realizar. Hablan de su formalidad, su
cordialidad y su atención respetuosa
"La enfermera es muy formal, le dice y le ex-
$\quad$ plica a uno bien las cosas, cómo debe tomarse
uno los medicamentos, para mi está bien así”.
(Indigena PG, 13-3:23)
La explicación y las respuestas de las enfermeras ante
las dudas suscitadas por el indígena también son ex-
presadas como actos de cuidado adecuado.
Otro factor con el que los indígenas se sienten bien
atendidos se relaciona con la formalidad y el respeto
en el cuidado que les brindan las enfermeras de salud
pública. Esta situación se expresa a través de: el salu-
do atento y amigable, el acercamiento físico educado,
la indagación holística y profunda sobre el estado de
salud percibida por los indígenas y lo que puede estar
afectando su tranquilidad.
$\quad$ "Atienden súper bien, la atención y como la
$\quad$ forma de ser de todos, lo reciben a uno con un
$\quad$ gesto amable, vea este momento: yo salí como
liviana con todo lo que dije. Sali muy bien, aquí
la atención es sobrada. Me siento súper bien”.
(Indigena CR, 13-13:18)
De igual forma, para los indígenas los gestos ami-
gables, las sonrisas, el contacto físico educado, la
atención a sus comentarios, las palabras amables y
la empatía de las enfermeras facilitan la labor. Con
estas actitudes son valoradas como buenas o malas
profesionales al momento de evaluar la atención y el
cuidado. Inclusive, si la enfermera durante la cita no
del indígena de asistir o no al control.

dados que deben realizar. Hablan de su formalidad, su
cordialidad y su atención respetuosa
"La enfermera es muy formal, le dice y le ex-
$\quad$ plica a uno bien las cosas, cómo debe tomarse
uno los medicamentos, para mi está bien así”.
(Indigena PG, 13-3:23)
La explicación y las respuestas de las enfermeras ante
las dudas suscitadas por el indígena también son ex-
presadas como actos de cuidado adecuado.
Otro factor con el que los indígenas se sienten bien
atendidos se relaciona con la formalidad y el respeto
en el cuidado que les brindan las enfermeras de salud
pública. Esta situación se expresa a través de: el salu-
do atento y amigable, el acercamiento físico educado,
la indagación holística y profunda sobre el estado de
salud percibida por los indígenas y lo que puede estar
afectando su tranquilidad.
$\quad$ "Atienden súper bien, la atención y como la
$\quad$ forma de ser de todos, lo reciben a uno con un
$\quad$ gesto amable, vea este momento: yo salí como
liviana con todo lo que dije. Sali muy bien, aquí
la atención es sobrada. Me siento súper bien”.
(Indigena CR, 13-13:18)
De igual forma, para los indígenas los gestos ami-
gables, las sonrisas, el contacto físico educado, la
atención a sus comentarios, las palabras amables y
la empatía de las enfermeras facilitan la labor. Con
estas actitudes son valoradas como buenas o malas
profesionales al momento de evaluar la atención y el
cuidado. Inclusive, si la enfermera durante la cita no
del indígena de asistir o no al control.

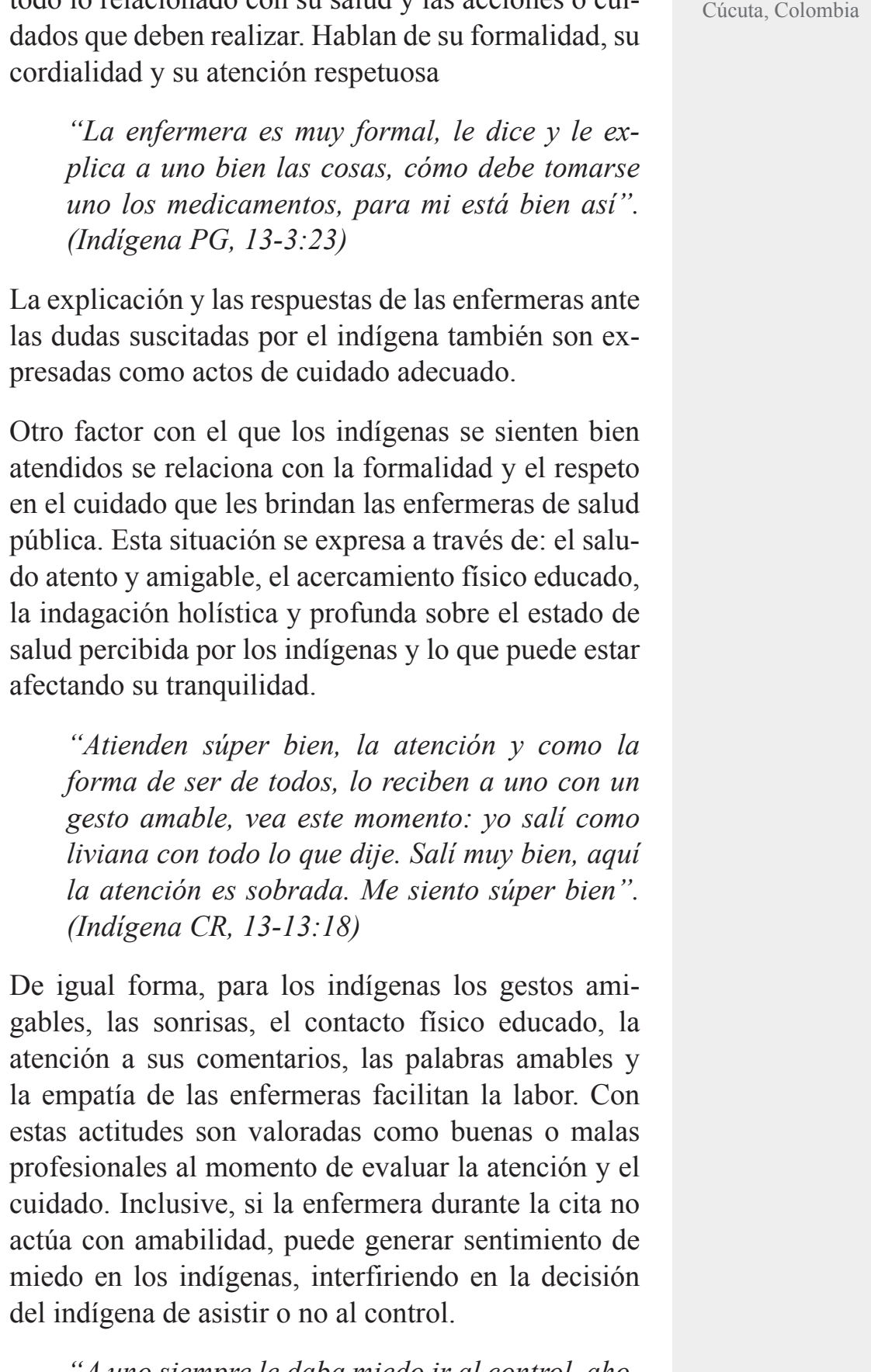

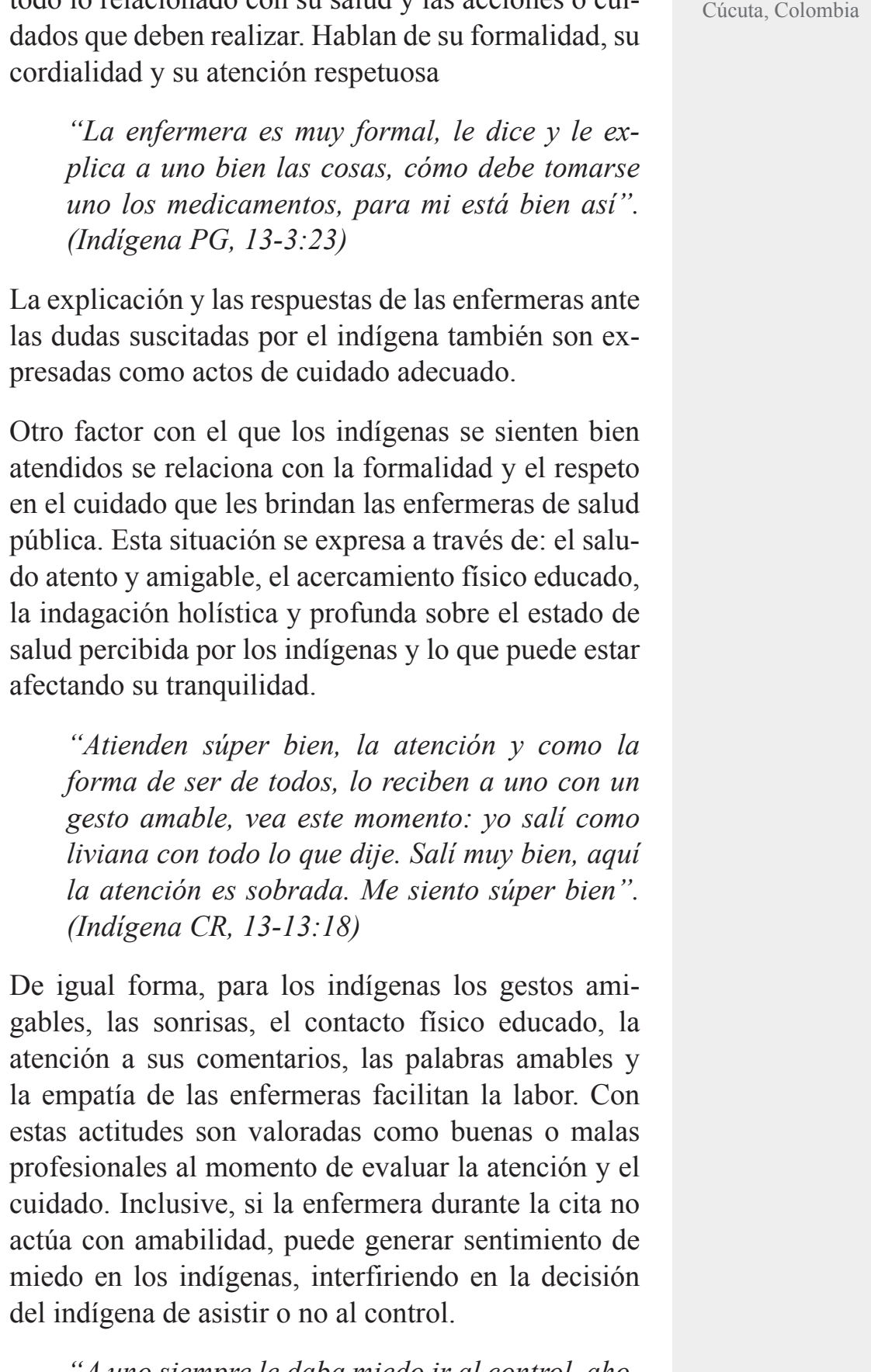

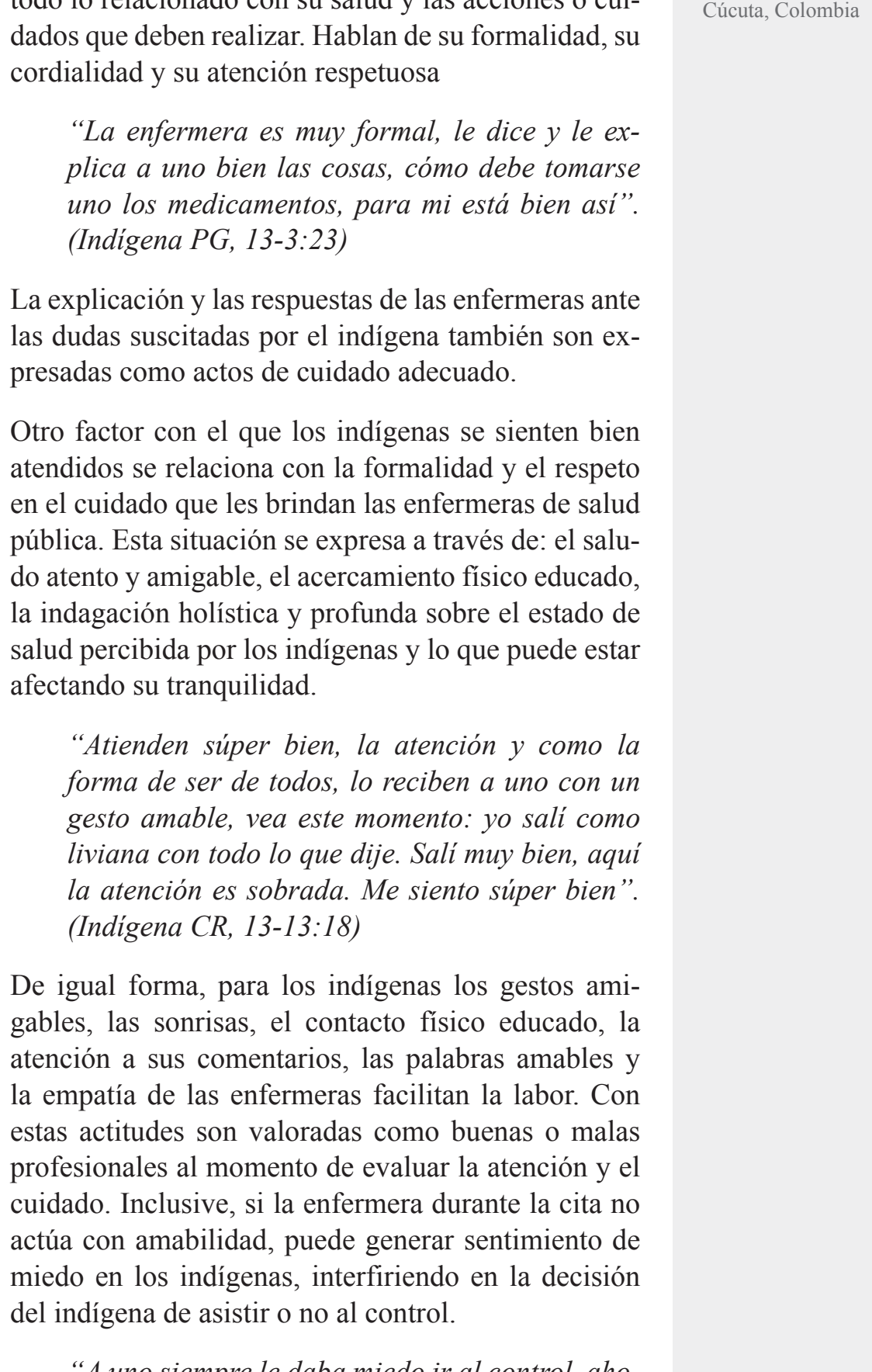

dados que deben realizar. Hablan de su formalidad, su
cordialidad y su atención respetuosa
"La enfermera es muy formal, le dice y le ex-
$\quad$ plica a uno bien las cosas, cómo debe tomarse
uno los medicamentos, para mi está bien así”.
(Indigena PG, 13-3:23)
La explicación y las respuestas de las enfermeras ante
las dudas suscitadas por el indígena también son ex-
presadas como actos de cuidado adecuado.
Otro factor con el que los indígenas se sienten bien
atendidos se relaciona con la formalidad y el respeto
en el cuidado que les brindan las enfermeras de salud
pública. Esta situación se expresa a través de: el salu-
do atento y amigable, el acercamiento físico educado,
la indagación holística y profunda sobre el estado de
salud percibida por los indígenas y lo que puede estar
afectando su tranquilidad.
$\quad$ "Atienden súper bien, la atención y como la
$\quad$ forma de ser de todos, lo reciben a uno con un
$\quad$ gesto amable, vea este momento: yo salí como
liviana con todo lo que dije. Sali muy bien, aquí
la atención es sobrada. Me siento súper bien”.
(Indigena CR, 13-13:18)
De igual forma, para los indígenas los gestos ami-
gables, las sonrisas, el contacto físico educado, la
atención a sus comentarios, las palabras amables y
la empatía de las enfermeras facilitan la labor. Con
estas actitudes son valoradas como buenas o malas
profesionales al momento de evaluar la atención y el
cuidado. Inclusive, si la enfermera durante la cita no
del indígena de asistir o no al control.

dados que deben realizar. Hablan de su formalidad, su
cordialidad y su atención respetuosa
"La enfermera es muy formal, le dice y le ex-
$\quad$ plica a uno bien las cosas, cómo debe tomarse
uno los medicamentos, para mi está bien así”.
(Indigena PG, 13-3:23)
La explicación y las respuestas de las enfermeras ante
las dudas suscitadas por el indígena también son ex-
presadas como actos de cuidado adecuado.
Otro factor con el que los indígenas se sienten bien
atendidos se relaciona con la formalidad y el respeto
en el cuidado que les brindan las enfermeras de salud
pública. Esta situación se expresa a través de: el salu-
do atento y amigable, el acercamiento físico educado,
la indagación holística y profunda sobre el estado de
salud percibida por los indígenas y lo que puede estar
afectando su tranquilidad.
$\quad$ "Atienden súper bien, la atención y como la
$\quad$ forma de ser de todos, lo reciben a uno con un
$\quad$ gesto amable, vea este momento: yo salí como
liviana con todo lo que dije. Sali muy bien, aquí
la atención es sobrada. Me siento súper bien”.
(Indigena CR, 13-13:18)
De igual forma, para los indígenas los gestos ami-
gables, las sonrisas, el contacto físico educado, la
atención a sus comentarios, las palabras amables y
la empatía de las enfermeras facilitan la labor. Con
estas actitudes son valoradas como buenas o malas
profesionales al momento de evaluar la atención y el
cuidado. Inclusive, si la enfermera durante la cita no
del indígena de asistir o no al control.

dados que deben realizar. Hablan de su formalidad, su
cordialidad y su atención respetuosa
"La enfermera es muy formal, le dice y le ex-
$\quad$ plica a uno bien las cosas, cómo debe tomarse
uno los medicamentos, para mi está bien así”.
(Indigena PG, 13-3:23)
La explicación y las respuestas de las enfermeras ante
las dudas suscitadas por el indígena también son ex-
presadas como actos de cuidado adecuado.
Otro factor con el que los indígenas se sienten bien
atendidos se relaciona con la formalidad y el respeto
en el cuidado que les brindan las enfermeras de salud
pública. Esta situación se expresa a través de: el salu-
do atento y amigable, el acercamiento físico educado,
la indagación holística y profunda sobre el estado de
salud percibida por los indígenas y lo que puede estar
afectando su tranquilidad.
$\quad$ "Atienden súper bien, la atención y como la
$\quad$ forma de ser de todos, lo reciben a uno con un
$\quad$ gesto amable, vea este momento: yo salí como
liviana con todo lo que dije. Sali muy bien, aquí
la atención es sobrada. Me siento súper bien”.
(Indigena CR, 13-13:18)
De igual forma, para los indígenas los gestos ami-
gables, las sonrisas, el contacto físico educado, la
atención a sus comentarios, las palabras amables y
la empatía de las enfermeras facilitan la labor. Con
estas actitudes son valoradas como buenas o malas
profesionales al momento de evaluar la atención y el
cuidado. Inclusive, si la enfermera durante la cita no
del indígena de asistir o no al control.

dados que deben realizar. Hablan de su formalidad, su
cordialidad y su atención respetuosa
"La enfermera es muy formal, le dice y le ex-
$\quad$ plica a uno bien las cosas, cómo debe tomarse
uno los medicamentos, para mi está bien así”.
(Indigena PG, 13-3:23)
La explicación y las respuestas de las enfermeras ante
las dudas suscitadas por el indígena también son ex-
presadas como actos de cuidado adecuado.
Otro factor con el que los indígenas se sienten bien
atendidos se relaciona con la formalidad y el respeto
en el cuidado que les brindan las enfermeras de salud
pública. Esta situación se expresa a través de: el salu-
do atento y amigable, el acercamiento físico educado,
la indagación holística y profunda sobre el estado de
salud percibida por los indígenas y lo que puede estar
afectando su tranquilidad.
$\quad$ "Atienden súper bien, la atención y como la
$\quad$ forma de ser de todos, lo reciben a uno con un
$\quad$ gesto amable, vea este momento: yo salí como
liviana con todo lo que dije. Sali muy bien, aquí
la atención es sobrada. Me siento súper bien”.
(Indigena CR, 13-13:18)
De igual forma, para los indígenas los gestos ami-
gables, las sonrisas, el contacto físico educado, la
atención a sus comentarios, las palabras amables y
la empatía de las enfermeras facilitan la labor. Con
estas actitudes son valoradas como buenas o malas
profesionales al momento de evaluar la atención y el
cuidado. Inclusive, si la enfermera durante la cita no
del indígena de asistir o no al control.

dados que deben realizar. Hablan de su formalidad, su
cordialidad y su atención respetuosa
"La enfermera es muy formal, le dice y le ex-
$\quad$ plica a uno bien las cosas, cómo debe tomarse
uno los medicamentos, para mi está bien así”.
(Indigena PG, 13-3:23)
La explicación y las respuestas de las enfermeras ante
las dudas suscitadas por el indígena también son ex-
presadas como actos de cuidado adecuado.
Otro factor con el que los indígenas se sienten bien
atendidos se relaciona con la formalidad y el respeto
en el cuidado que les brindan las enfermeras de salud
pública. Esta situación se expresa a través de: el salu-
do atento y amigable, el acercamiento físico educado,
la indagación holística y profunda sobre el estado de
salud percibida por los indígenas y lo que puede estar
afectando su tranquilidad.
$\quad$ "Atienden súper bien, la atención y como la
$\quad$ forma de ser de todos, lo reciben a uno con un
$\quad$ gesto amable, vea este momento: yo salí como
liviana con todo lo que dije. Sali muy bien, aquí
la atención es sobrada. Me siento súper bien”.
(Indigena CR, 13-13:18)
De igual forma, para los indígenas los gestos ami-
gables, las sonrisas, el contacto físico educado, la
atención a sus comentarios, las palabras amables y
la empatía de las enfermeras facilitan la labor. Con
estas actitudes son valoradas como buenas o malas
profesionales al momento de evaluar la atención y el
cuidado. Inclusive, si la enfermera durante la cita no
del indígena de asistir o no al control.

dados que deben realizar. Hablan de su formalidad, su
cordialidad y su atención respetuosa
"La enfermera es muy formal, le dice y le ex-
$\quad$ plica a uno bien las cosas, cómo debe tomarse
uno los medicamentos, para mi está bien así”.
(Indigena PG, 13-3:23)
La explicación y las respuestas de las enfermeras ante
las dudas suscitadas por el indígena también son ex-
presadas como actos de cuidado adecuado.
Otro factor con el que los indígenas se sienten bien
atendidos se relaciona con la formalidad y el respeto
en el cuidado que les brindan las enfermeras de salud
pública. Esta situación se expresa a través de: el salu-
do atento y amigable, el acercamiento físico educado,
la indagación holística y profunda sobre el estado de
salud percibida por los indígenas y lo que puede estar
afectando su tranquilidad.
$\quad$ "Atienden súper bien, la atención y como la
$\quad$ forma de ser de todos, lo reciben a uno con un
$\quad$ gesto amable, vea este momento: yo salí como
liviana con todo lo que dije. Sali muy bien, aquí
la atención es sobrada. Me siento súper bien”.
(Indigena CR, 13-13:18)
De igual forma, para los indígenas los gestos ami-
gables, las sonrisas, el contacto físico educado, la
atención a sus comentarios, las palabras amables y
la empatía de las enfermeras facilitan la labor. Con
estas actitudes son valoradas como buenas o malas
profesionales al momento de evaluar la atención y el
cuidado. Inclusive, si la enfermera durante la cita no
del indígena de asistir o no al control.

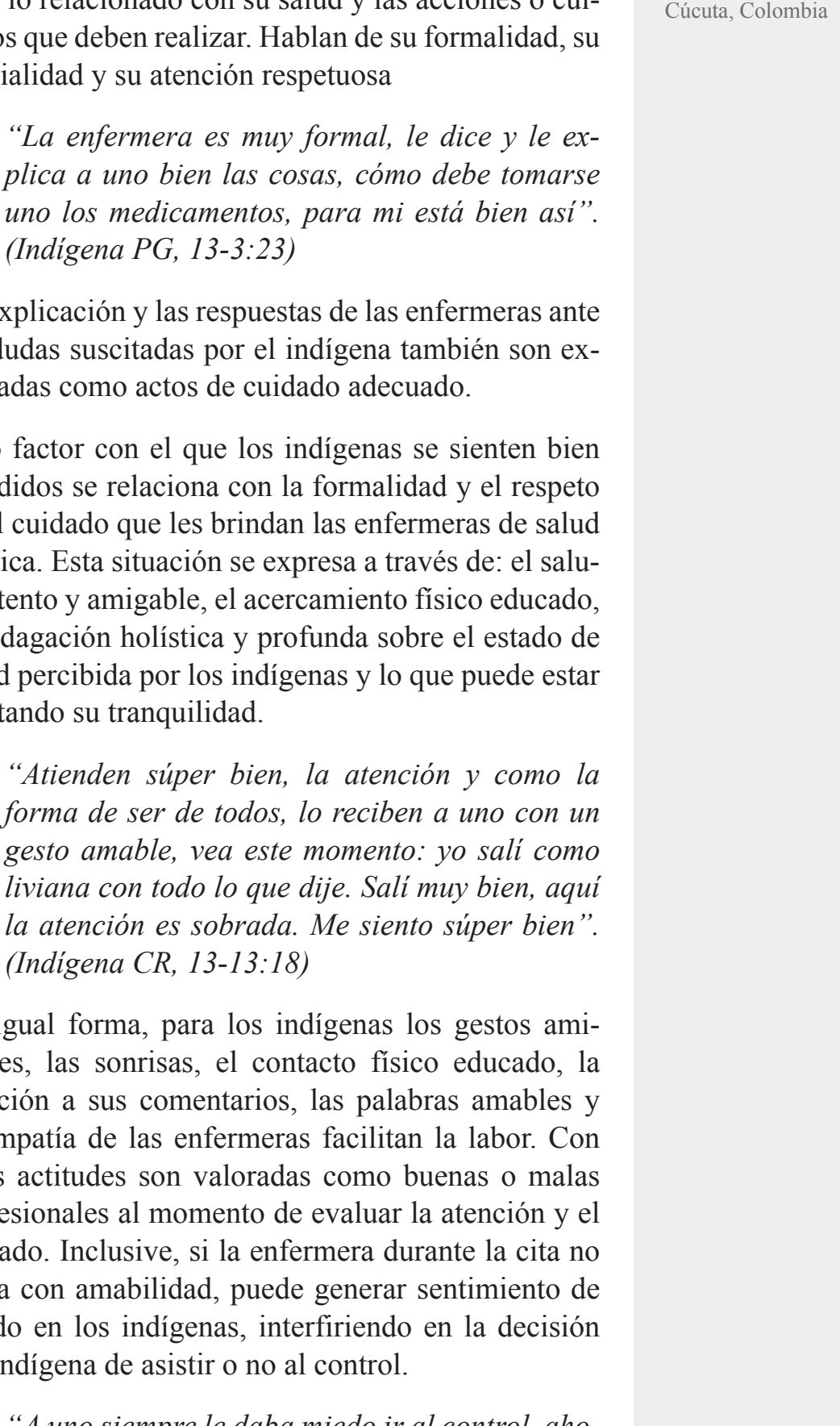

Cúcuta, Colombia
"La enfermera es muy formal, le dice y le ex-
plica a uno bien las cosas, cómo debe tomarse
uno los medicamentos, para mi está bien así".
(Indigena PG, 13-3:23)
explicación y las respuestas de las enfermeras ante
dudas suscitadas por el indígena también son ex-
fadas como actos de cuidado adecuado.
factor con el que los indígenas se sienten bien
lidos se relaciona con la formalidad y el respeto
lica. Esta situación se expresa a través de: el salu-
ndagación holística y profunda sobre el estado de
"A percibida por los indígenas y lo que puede estar
"Atienden súper bien, la atención y como la
forma de ser de todos, lo reciben a uno con un
gesto amable, vea este momento: yo sali como
liviana con todo lo que dije. Sali muy bien, aquí
la atención es sobrada. Me siento súper bien”.
(Indigena CR, 13-13:18)

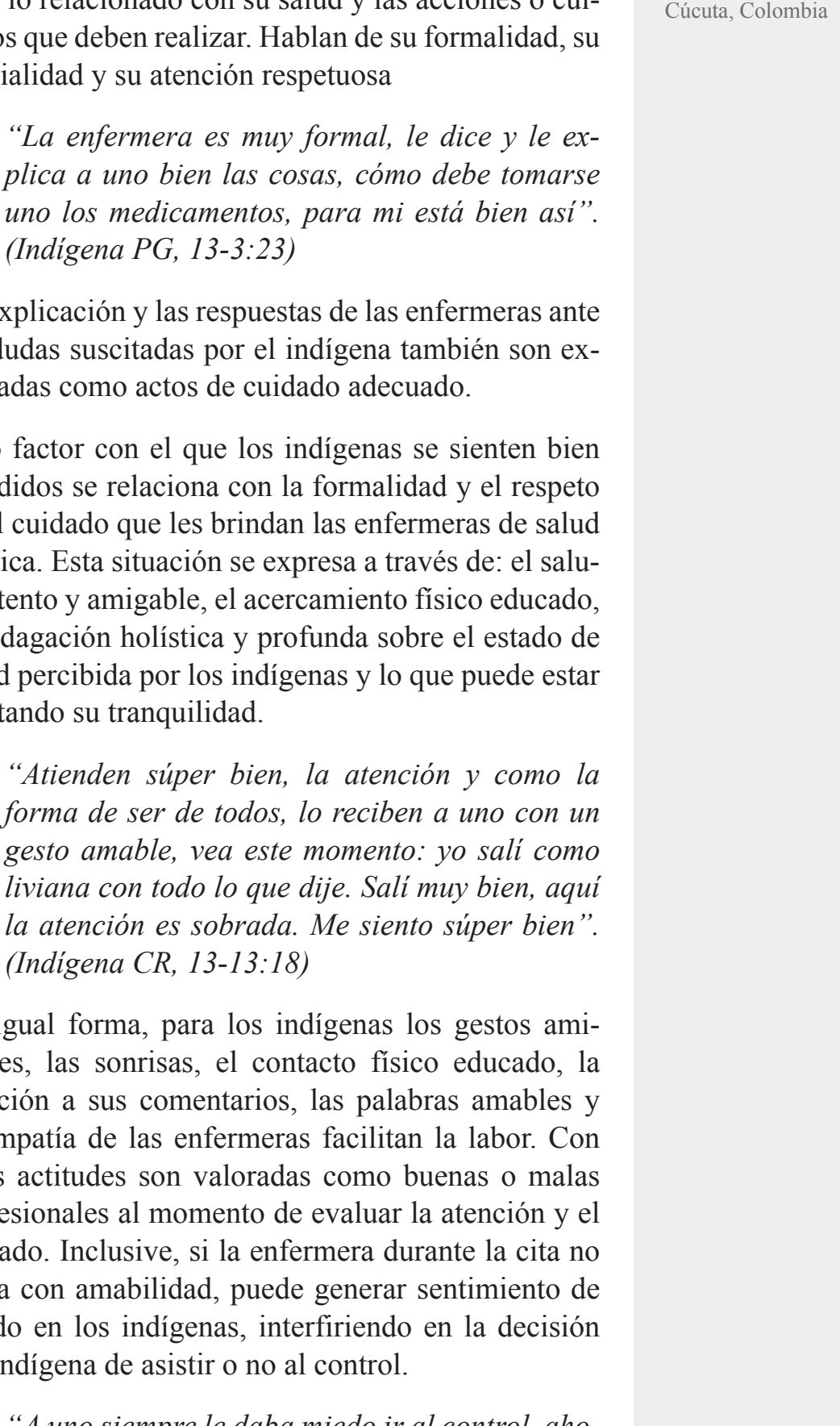

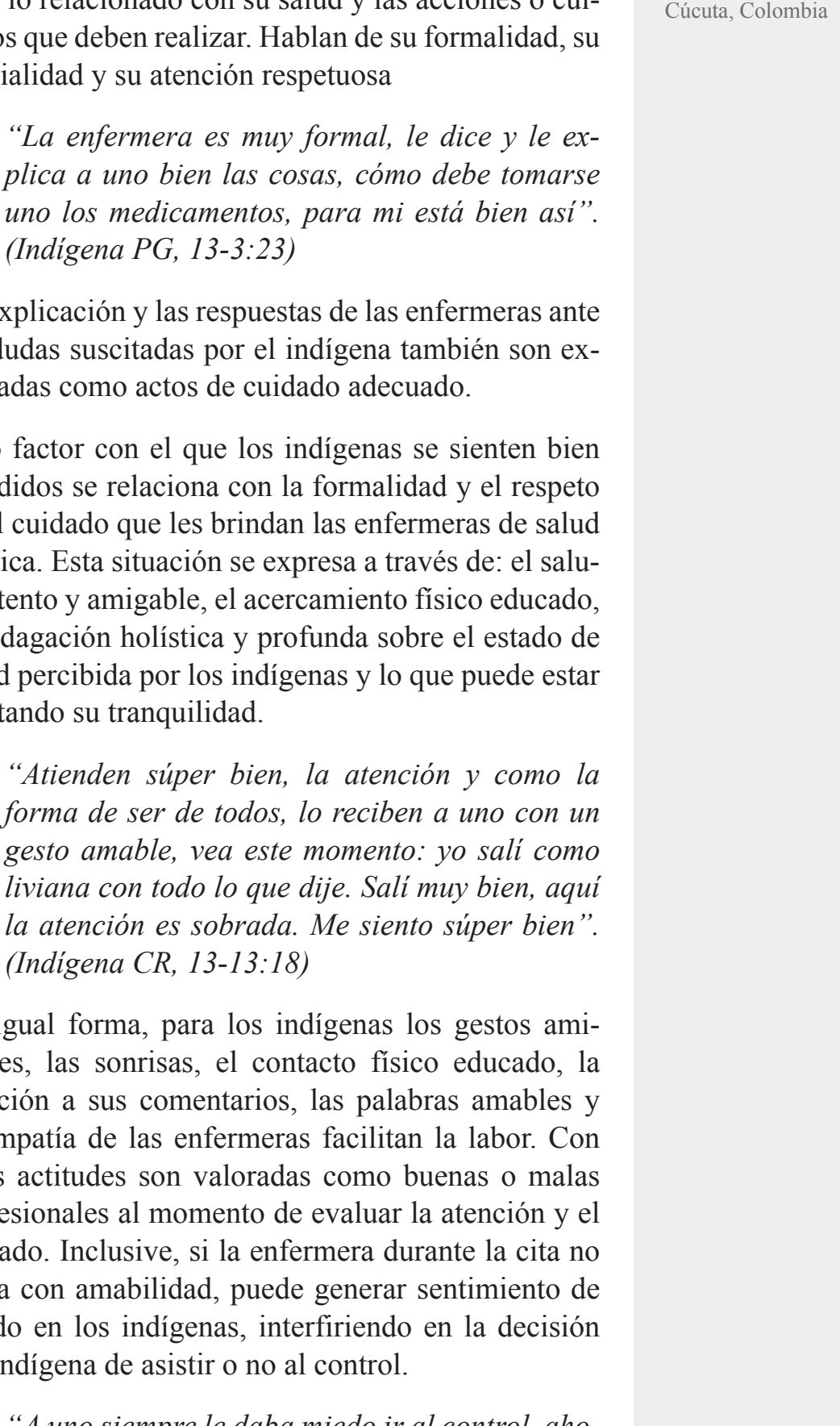

"La enfermera es muy formal, le dice y le ex-
plica a uno bien las cosas, cómo debe tomarse
uno los medicamentos, para mi está bien así.
(Indígena PG, 13-3:23)
xplicación y las respuestas de las enfermeras ante
dudas suscitadas por el indígena también son ex-
adas como actos de cuidado adecuado.
factor con el que los indígenas se sienten bien
didos se relaciona con la formalidad y el respeto
cuidado que les brindan las enfermeras de salud
ica. Esta situación se expresa a través de: el salu-
danto y amigable, el acercamiento físico educado,
d percibida por los indígenas y lo que puede estar
"Atienden súper bien, la atención y como la
forma de ser de todos, lo reciben a uno con un
gesto amable, vea este momento: yo salí como
liviana con todo lo que dije. Sali muy bien, aquí
la atención es sobrada. Me siento súper bien”.
(Indígena CR, 13-13:18)
gual forma, para los indígenas los gestos ami-
es, las sonrisas, el contacto físico educado, la
ción a sus comentarios, las palabras amables y
mpatía de las enfermeras facilitan la labor. Con
actitudes son valoradas como buenas o malas
adionales al momento de evaluar la atención y el
ado. Inclusive, si la enfermera durante la cita no
con amabilidad, puede generar sentimiento de
ando su tranquilidad.

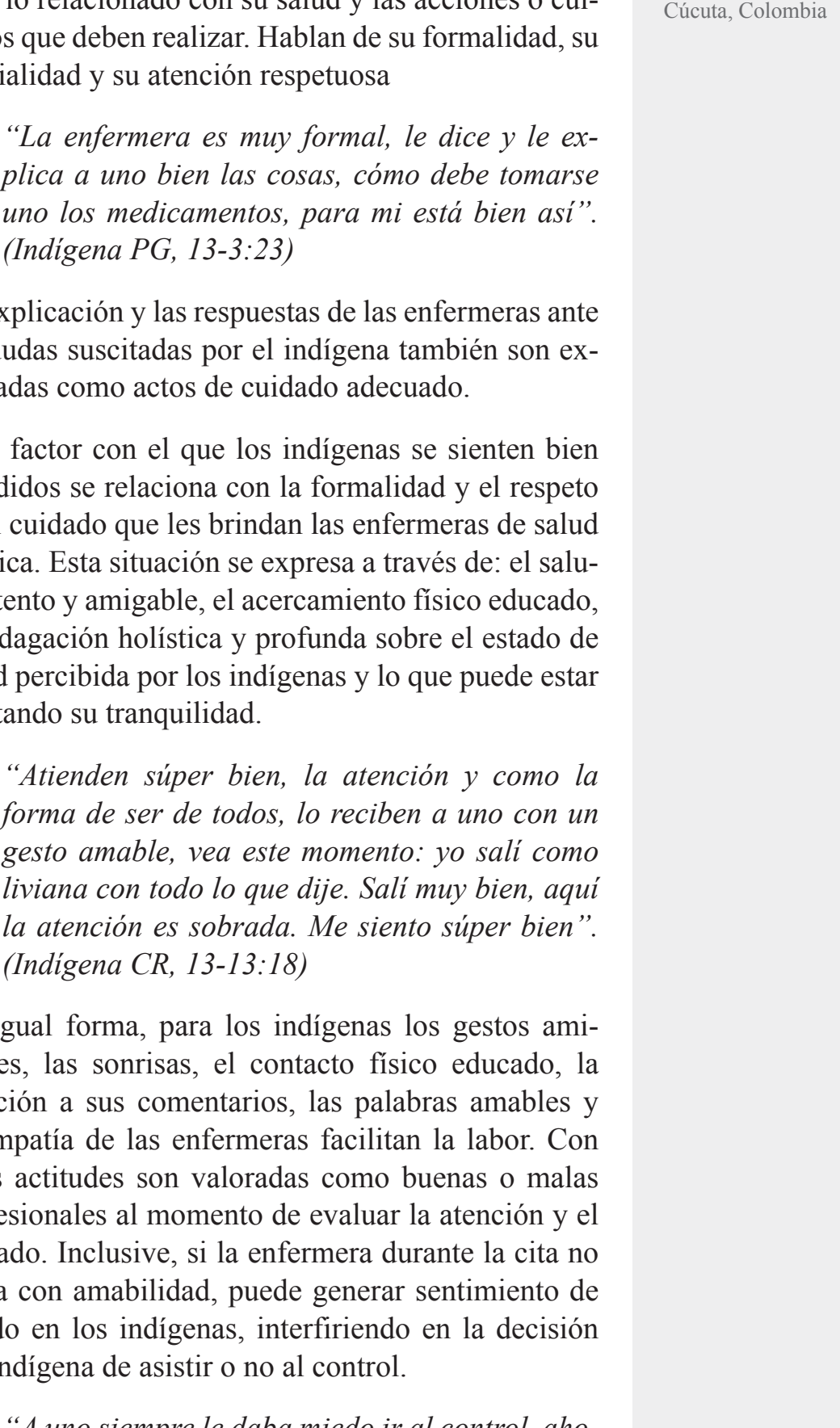

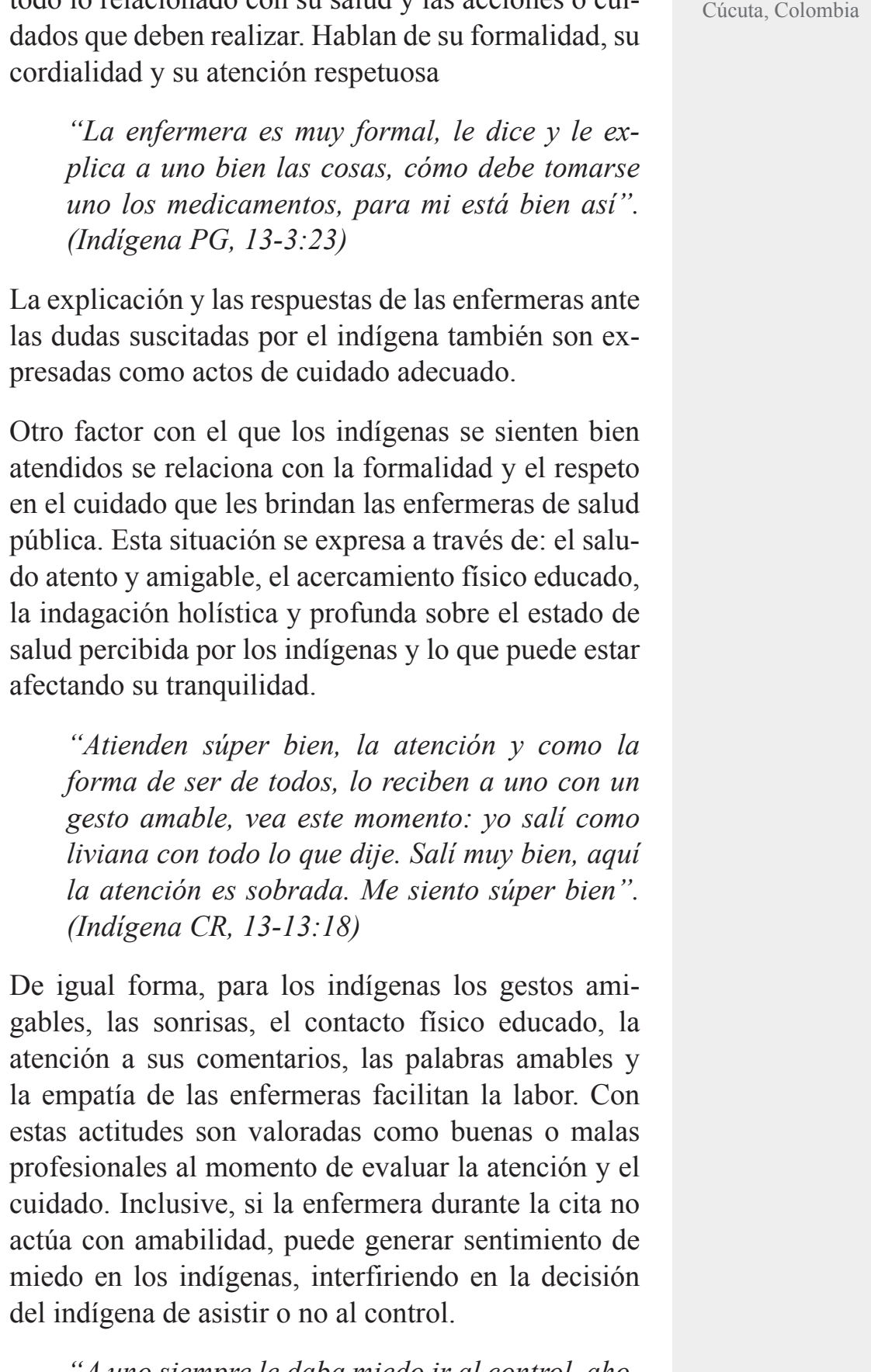

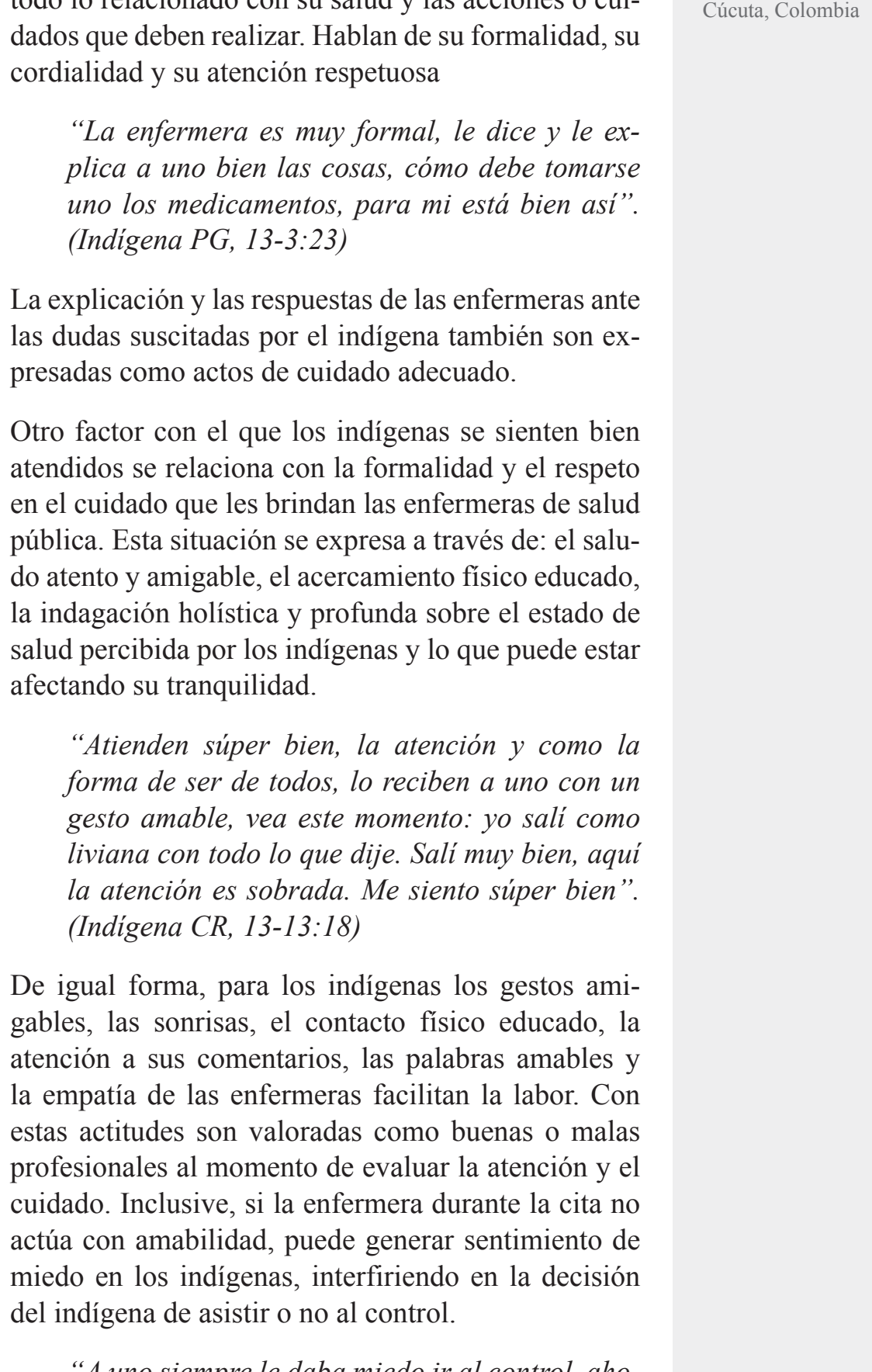

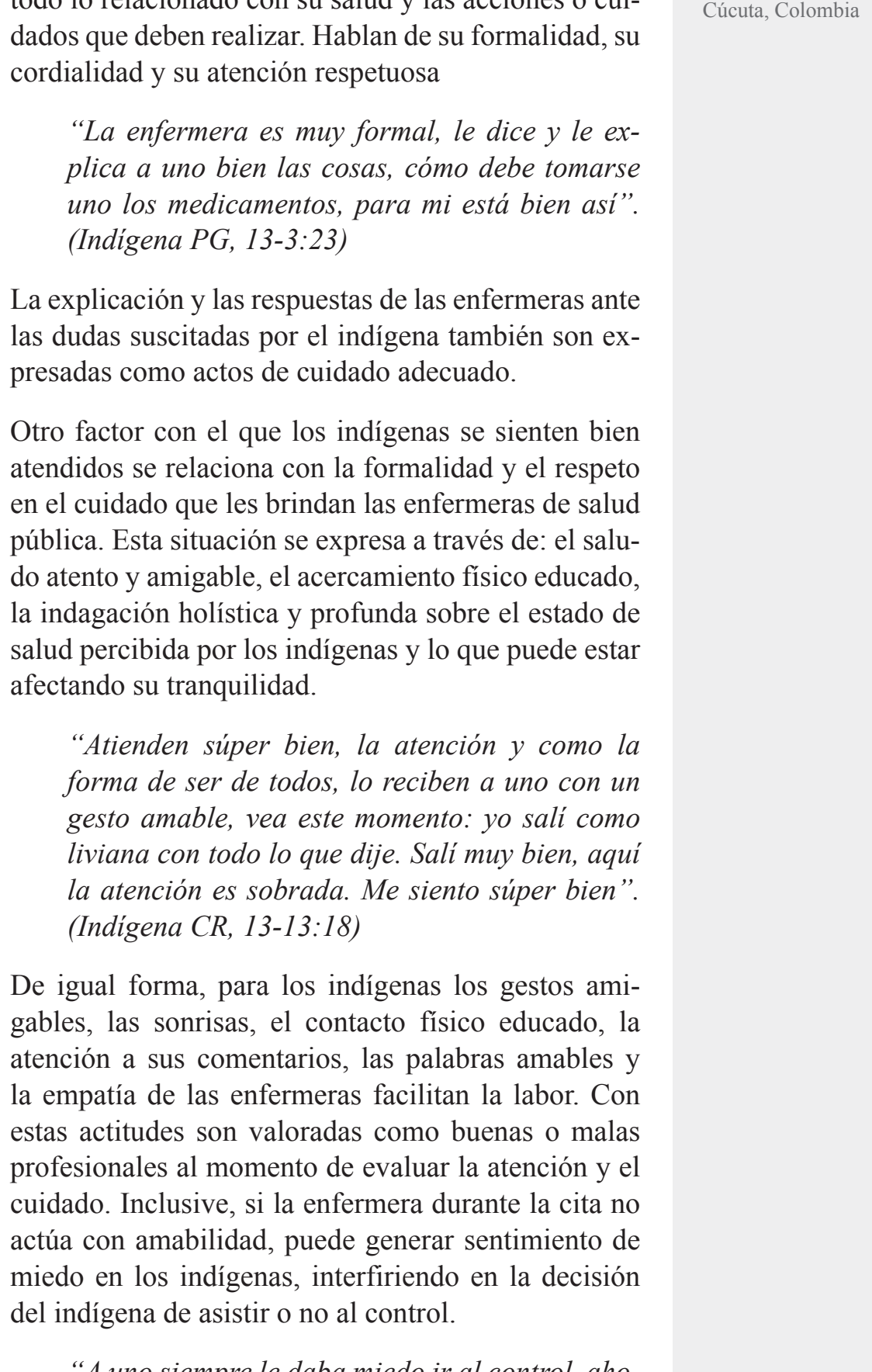

dados que deben realizar. Hablan de su formalidad, su
cordialidad y su atención respetuosa
"La enfermera es muy formal, le dice y le ex-
$\quad$ plica a uno bien las cosas, cómo debe tomarse
uno los medicamentos, para mi está bien así”.
(Indigena PG, 13-3:23)
La explicación y las respuestas de las enfermeras ante
las dudas suscitadas por el indígena también son ex-
presadas como actos de cuidado adecuado.
Otro factor con el que los indígenas se sienten bien
atendidos se relaciona con la formalidad y el respeto
en el cuidado que les brindan las enfermeras de salud
pública. Esta situación se expresa a través de: el salu-
do atento y amigable, el acercamiento físico educado,
la indagación holística y profunda sobre el estado de
salud percibida por los indígenas y lo que puede estar
afectando su tranquilidad.
$\quad$ "Atienden súper bien, la atención y como la
$\quad$ forma de ser de todos, lo reciben a uno con un
$\quad$ gesto amable, vea este momento: yo salí como
liviana con todo lo que dije. Sali muy bien, aquí
la atención es sobrada. Me siento súper bien”.
(Indigena CR, 13-13:18)
De igual forma, para los indígenas los gestos ami-
gables, las sonrisas, el contacto físico educado, la
atención a sus comentarios, las palabras amables y
la empatía de las enfermeras facilitan la labor. Con
estas actitudes son valoradas como buenas o malas
profesionales al momento de evaluar la atención y el
cuidado. Inclusive, si la enfermera durante la cita no
del indígena de asistir o no al control.

dados que deben realizar. Hablan de su formalidad, su
cordialidad y su atención respetuosa
"La enfermera es muy formal, le dice y le ex-
$\quad$ plica a uno bien las cosas, cómo debe tomarse
uno los medicamentos, para mi está bien así”.
(Indigena PG, 13-3:23)
La explicación y las respuestas de las enfermeras ante
las dudas suscitadas por el indígena también son ex-
presadas como actos de cuidado adecuado.
Otro factor con el que los indígenas se sienten bien
atendidos se relaciona con la formalidad y el respeto
en el cuidado que les brindan las enfermeras de salud
pública. Esta situación se expresa a través de: el salu-
do atento y amigable, el acercamiento físico educado,
la indagación holística y profunda sobre el estado de
salud percibida por los indígenas y lo que puede estar
afectando su tranquilidad.
$\quad$ "Atienden súper bien, la atención y como la
$\quad$ forma de ser de todos, lo reciben a uno con un
$\quad$ gesto amable, vea este momento: yo salí como
liviana con todo lo que dije. Sali muy bien, aquí
la atención es sobrada. Me siento súper bien”.
(Indigena CR, 13-13:18)
De igual forma, para los indígenas los gestos ami-
gables, las sonrisas, el contacto físico educado, la
atención a sus comentarios, las palabras amables y
la empatía de las enfermeras facilitan la labor. Con
estas actitudes son valoradas como buenas o malas
profesionales al momento de evaluar la atención y el
cuidado. Inclusive, si la enfermera durante la cita no
del indígena de asistir o no al control.

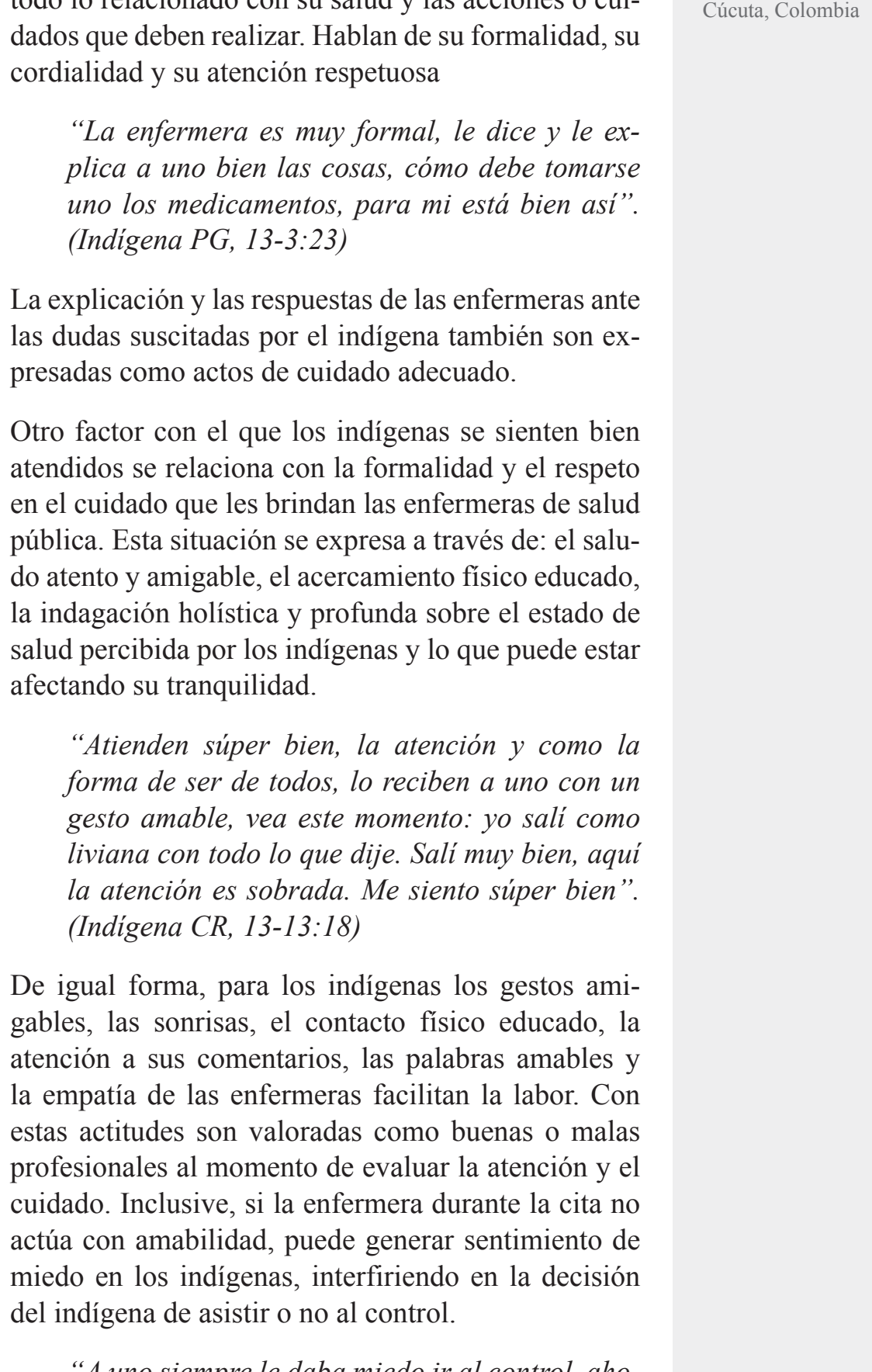

dados que deben realizar. Hablan de su formalidad, su
cordialidad y su atención respetuosa
"La enfermera es muy formal, le dice y le ex-
$\quad$ plica a uno bien las cosas, cómo debe tomarse
uno los medicamentos, para mi está bien así”.
(Indigena PG, 13-3:23)
La explicación y las respuestas de las enfermeras ante
las dudas suscitadas por el indígena también son ex-
presadas como actos de cuidado adecuado.
Otro factor con el que los indígenas se sienten bien
atendidos se relaciona con la formalidad y el respeto
en el cuidado que les brindan las enfermeras de salud
pública. Esta situación se expresa a través de: el salu-
do atento y amigable, el acercamiento físico educado,
la indagación holística y profunda sobre el estado de
salud percibida por los indígenas y lo que puede estar
afectando su tranquilidad.
$\quad$ "Atienden súper bien, la atención y como la
$\quad$ forma de ser de todos, lo reciben a uno con un
$\quad$ gesto amable, vea este momento: yo salí como
liviana con todo lo que dije. Sali muy bien, aquí
la atención es sobrada. Me siento súper bien”.
(Indigena CR, 13-13:18)
De igual forma, para los indígenas los gestos ami-
gables, las sonrisas, el contacto físico educado, la
atención a sus comentarios, las palabras amables y
la empatía de las enfermeras facilitan la labor. Con
estas actitudes son valoradas como buenas o malas
profesionales al momento de evaluar la atención y el
cuidado. Inclusive, si la enfermera durante la cita no
del indígena de asistir o no al control.

dados que deben realizar. Hablan de su formalidad, su
cordialidad y su atención respetuosa
"La enfermera es muy formal, le dice y le ex-
$\quad$ plica a uno bien las cosas, cómo debe tomarse
uno los medicamentos, para mi está bien así”.
(Indigena PG, 13-3:23)
La explicación y las respuestas de las enfermeras ante
las dudas suscitadas por el indígena también son ex-
presadas como actos de cuidado adecuado.
Otro factor con el que los indígenas se sienten bien
atendidos se relaciona con la formalidad y el respeto
en el cuidado que les brindan las enfermeras de salud
pública. Esta situación se expresa a través de: el salu-
do atento y amigable, el acercamiento físico educado,
la indagación holística y profunda sobre el estado de
salud percibida por los indígenas y lo que puede estar
afectando su tranquilidad.
$\quad$ "Atienden súper bien, la atención y como la
$\quad$ forma de ser de todos, lo reciben a uno con un
$\quad$ gesto amable, vea este momento: yo salí como
liviana con todo lo que dije. Sali muy bien, aquí
la atención es sobrada. Me siento súper bien”.
(Indigena CR, 13-13:18)
De igual forma, para los indígenas los gestos ami-
gables, las sonrisas, el contacto físico educado, la
atención a sus comentarios, las palabras amables y
la empatía de las enfermeras facilitan la labor. Con
estas actitudes son valoradas como buenas o malas
profesionales al momento de evaluar la atención y el
cuidado. Inclusive, si la enfermera durante la cita no
del indígena de asistir o no al control.

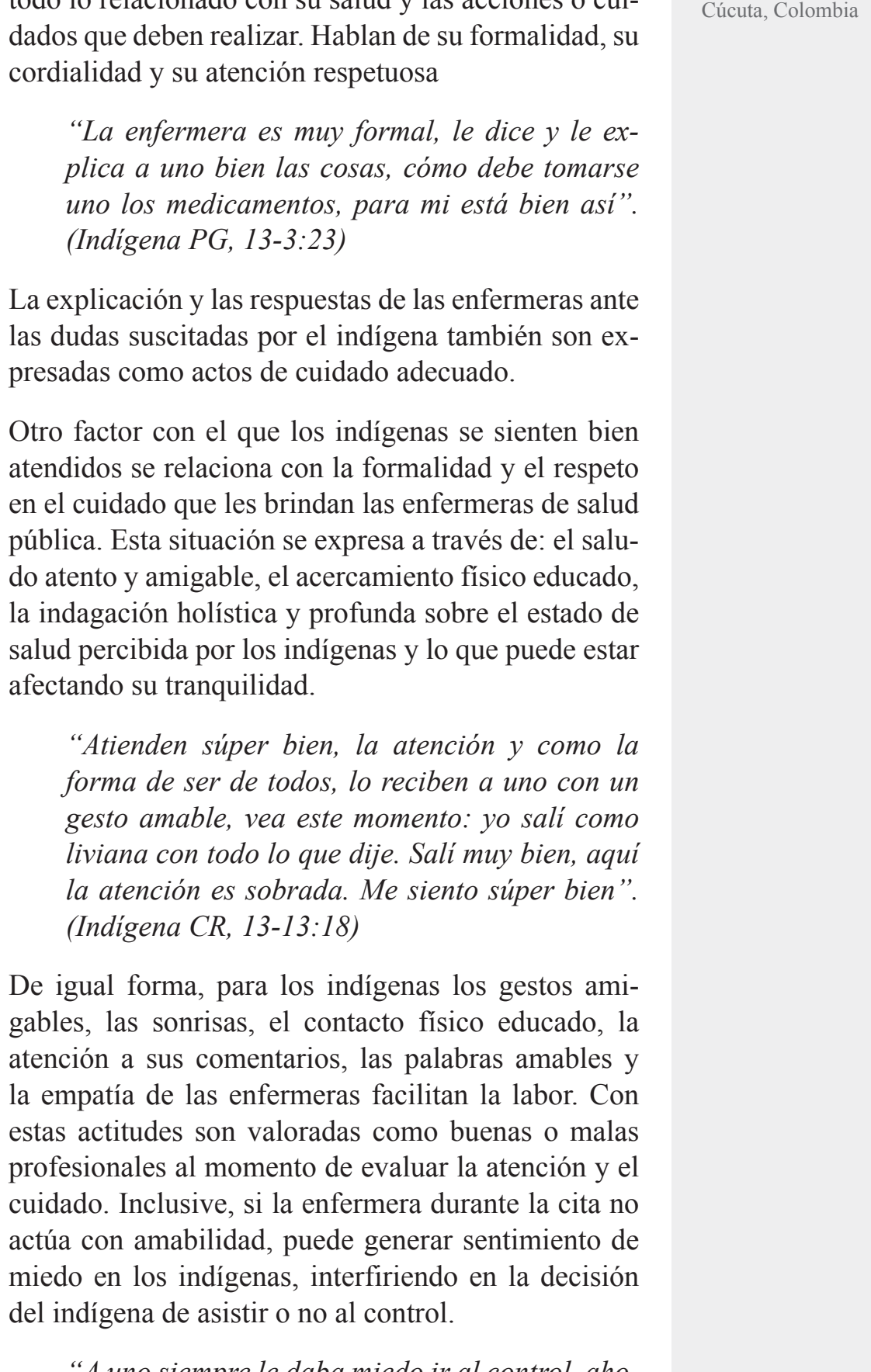

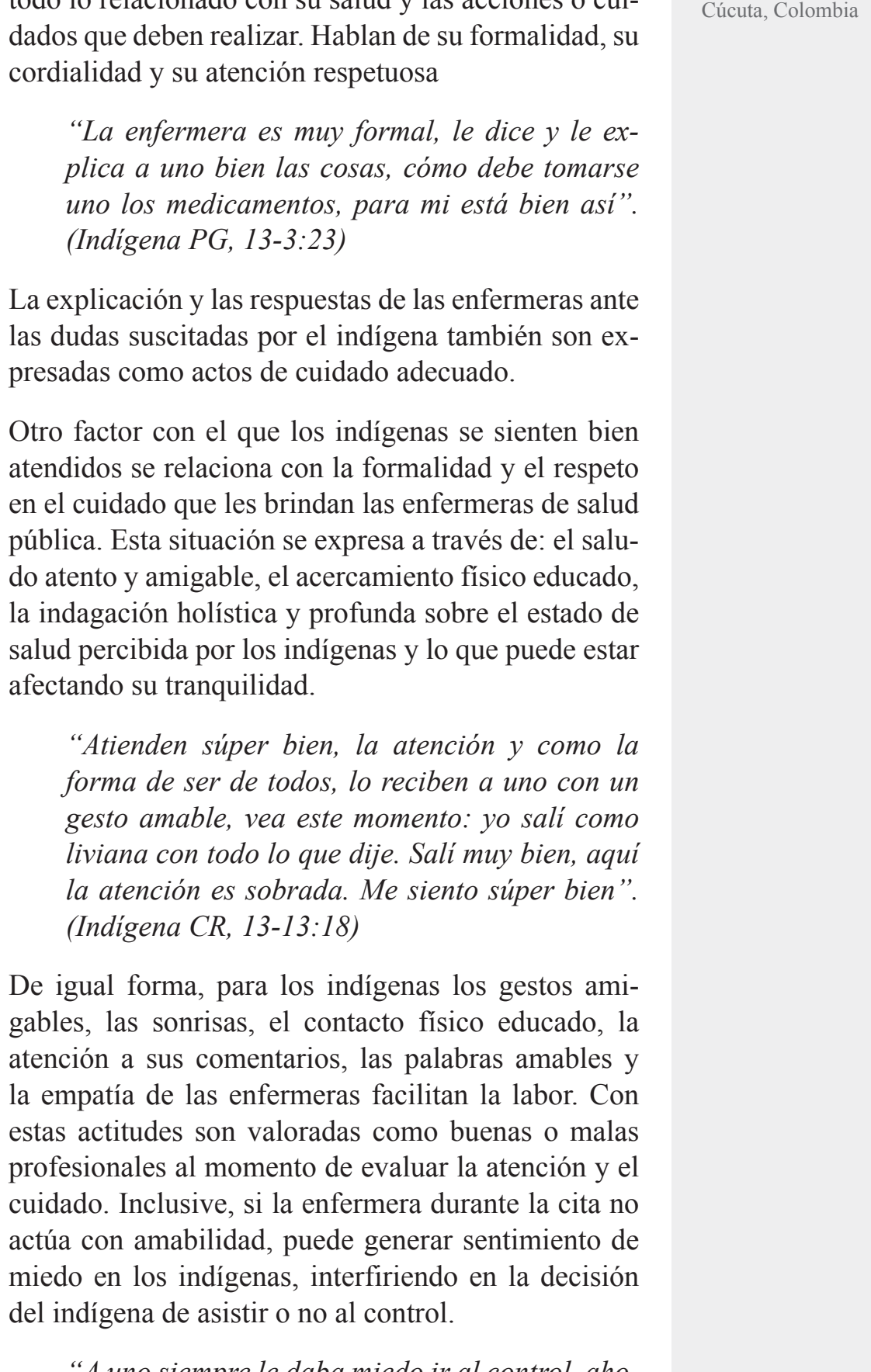

"A uno siempre le daba miedo ir al control, ahora años siempre era como esa rabia, a uno le daba susto asistir porque siempre era como tratándolo a uno como de mala gana o yo no sé... (Indigena LP, 28-75:24)

El tiempo, la disposición y la escucha que se dedica en el control por parte de las enfermeras son factores que producen sensación de un cuidado adecuado en 
ISSN-PRINT

1794-9831

E-ISSN 2322-7028

Vol. 16 No. 2

May - Ago 2019

Cúcuta, Colombia los Embera Chamí. De manera especial, las mujeres indígenas manifiestan gratificación cuando las enfermeras se brindan para escuchar otros aspectos no ajustados a los objetivos del control y que tienen que ver con su cotidianidad.

"Bien, no, bien. A lo bien, porque yo a ustedes les conté, a mí me ayudó a salir adelante con ella, fue, la enfermera María Gañán. ¡Ay!, ella es muy linda, bella gente, ;ay, no sé! Uno a veces llega muy desmotivado en muchas cosas y ella ese día me vio llegar y me dijo: «no»... Lo linda la forma de ser". (Indígena CR, 28-78:23)

También, los indígenas Embera Chamí, al expresar su gusto por el cuidado recibido de las enfermeras, con frecuencia lo relacionan con otros momentos diferentes al encuentro del cuidado y a varios asuntos externos de índole institucional. Aspectos como el acceso a las citas, la atención oportuna, los tiempos de espera, la amabilidad y la resolución de sus situaciones son de gran importancia.

"En varias oportunidades ha pasado que cuando pregunto por la atención de la enfermera, los indigenas terminan hablando de aspectos institucionales como pedir las citas por teléfono, o que no los ponen a esperar". (Observación participante, 24-68:18)

\section{Subcategoría 1.2: Como Embera, en ocasiones me molesta esperar la atención}

Una característica de los indígenas Embera Chamí, con relación a la percepción del cuidado recibido de las enfermeras de salud pública, se vincula con la molestia que les causa algunos tiempos de espera momentos precedentes a la atención. Los indígenas de manera previa, solicitan y programan el encuentro para ser atendidos en los controles. La IPS en donde se realizó la investigación tiene estipulados 40 minutos para cada control, situación que conlleva, en términos generales, que se cumplan los horarios acordados. Sin embargo, cuando por alguna eventualidad les corresponda esperar, con frecuencia lo expresan en forma de disgusto e insatisfacción.

"Ingresa al control el papá y la mamá con la niña de un año. Los padres entran con una actitud brava, alterados, manifiestan que se demoraron mucho en llamarlos y la niña ya está cansada". (Observación participante, 13-68:1)
Además, para los Embera Chamí el tiempo de espera hace parte de su concepción sobre el sentirse bien atendidos. Actualmente, el tiempo de espera para recibir atención en los servicios de salud forma parte de los recuerdos constantes y desagradables vividos con anterioridad en otra institución de salud, ya que se la compara con otros establecimientos de atención, por tanto valoran que en la IPS intercultural se cumplan con los horarios estipulados.

"Me siento bien atendida, vea, siempre lo tratan a uno bien, le explican a uno las cosas y todo eso. Porque muchas veces una va a otra parte y lo hacen esperar a uno mucho, no lo atienden a la hora que es y todo eso". (Indigena TS, 28-97:12)

Resulta interesante destacar, que la insatisfacción ante la espera se observa con mayor intensidad en los controles realizados en el área urbana, pues la mayoría de los indígenas que viven en la ciudad deben responder por sus empleos u obligaciones laborales, así como por los compromisos sociales y familiares que les limitan el tiempo disponible para el control. Por su parte, los indígenas de la zona rural que deciden asistir a los controles en la zona urbana -por proximidad o por no disponer de atención cerca de su comunidad- se les dificulta el regreso a sus hogares, además de tener el tiempo limitado para realizar otras actividades como la obtención de alimentos no perecederos, elementos de aseo, compra de indumentaria, visita a familiares, entre otros.

Categoría 2: Como un Embera intentó seguir las recomendaciones de la enfermera, aunque las de la comida se le dificultaron

En este caso se demuestra la disposición, la intención y el deseo del indígena de adaptarse a los cuidados indicados por las enfermeras; aunque ello contrasta con la dificultad que le ocasiona llevar a cabo las modificaciones sobre los hábitos alimenticios. Además, se observa el aumento o mantenimiento de la asistencia a los controles, situación que repercute de manera positiva en la disminución de pacientes que asisten, lo que mejora las metas institucionales.

Subcategoría 2.1: Cómo un Embera intentó seguir las recomendaciones de la enfermera y regresó al control

Debe indicarse, que en los asuntos no verbales, los Embera durante y posterior a la realización del con- 
trol entienden, acatan, recuerdan y aspiran a cumplir las indicaciones o cuidados planteados por las enfermeras. No obstante, en ocasiones pueden perder algunos detalles.

Por otra parte, cuando tienen claro que una recomendación indicada por las enfermeras no pueden cumplirla por razones económicas, sociales, geográficas, religiosas o culturales, lo expresan en la consulta con el objeto de buscar otras opciones. Si la recomendación en definitiva no puede ser realizada por el indígena por motivos personales, él o ella simplemente escuchará.

"Jum, mamita, pero yo para ir a buscar una promotora tengo que ir de aquí a la Conchinchina [sic]". (Indigena CR, 28-11:33)

Lo más significativo, es que las indicaciones percibidas con más interés y cumplimiento por parte de los indígenas son las realizadas en los controles de crecimiento y desarrollo. Las madres, al ser las principales cuidadoras y acompañantes en dichos controles, tienen una actitud receptiva y muestran especial interés por aprender sobre todo lo relacionado con los cuidados que aumentan la salud, el bienestar, el crecimiento y el desarrollo de sus hijos.

"Al niño me le descubrieron en Manizales que tenía gastritis infantil, le mandaron 90 pastas de omeprazol por tres meses, entonces resulta y pasa que eso allá no me lo dieron. Entonces yo bajaba cada tres días al pueblo a comprar las benditas pastas". (Indígena CR, 28-95:91)

Respecto al manejo de la hipertensión arterial, se observa en los indígenas que mezclan medicamentos naturales (en especial de bebidas con plantas medicinales recomendadas por médicos tradicionales, familiares o amigos) con medicamentos occidentales ofrecidos de manera gratuita por la institución prestadora de servicios de salud, aunque tienen mayor preferencia y aceptación hacia los primeros.

"Yo de miedo de la presión alta, empezaron a decirme que tome de esto y de tal cosa. Yo con el miedo de tomar las pastas, yo tomaba muchas bebidas. A mi me decían que savia china, pa' la presión, que cidra [sic]" (Indigena LP, 28-157:18)

Se debe tener en cuenta, que aunque los indígenas aceptan las indicaciones señaladas por las enfermeras sobre la importancia de: adquirir estilos de vida saludables, incrementar el consumo de frutas y verduras, ingerir agua y aumentar el ejercicio o la actividad física; sin embargo, no son actos realizados con regularidad por el indígena Embera Chamí, ya sea por imposibilidad, falta de costumbre o voluntad, aún a pesar de que son conscientes de sus beneficios. Esta situación interfiere de manera directa en el estado de salud y de manera especial en los indicadores asociados a la patología relacionada con la hipertensión arterial

"La investigadora le pregunta a una de las mamás si está haciendo las recomendaciones que le dio la enfermera en la consulta pasada sobre la alimentación. La indígena dice que ninguna, la enfermera interviene diciéndole que, si consume manteca por no tener dinero para el aceite o por costumbre, la indigena dice que por costumbre. (Observación participante, 28-61:7).

Con relación a los métodos de planificación familiar (un acto propio de las mujeres indígenas) se observa que las mujeres se muestran interesadas y con voluntad para cumplir las recomendaciones dadas por las enfermeras. Sin embargo, este interés se puede ver obstaculizado por las dificultades de acceso al método o a la influencia de sus parejas para no planificar, pues los hombres indígenas ven la planificación familiar como una amenaza contra la monogamia

Otro factor que surge de manera inconsciente entre ambos actores -enfermeras e indígenas- es la posibilidad de verse reflejados en las bondades de la acción que se pretende realizar. Esta situación despierta un sentimiento de confort y confianza, permitiendo que se confirme el deseo de seguir la indicación de manera más tranquila y definitiva.

"La enfermera, es una belleza, me subió los ánimos y me dijo que no le dejara colocar los audifonos, bueno ella me dijo yo tengo el mismo problema y aquí estoy y eche pa' lante con ese niño". (Indigena CR, 13-13:16)

También se percibe, que la forma de cuidado por parte de las enfermeras estimula en los Embera cambios a nivel personal reflejados en las metas institucionales. Al respecto, se puede observar que con esta forma de cuidado los indígenas tienen mayor adherencia a los controles, lo que al mismo tiempo produce un cambio en su intención de presentarse al control. Así, el indígena ya no asiste pensando en que es un deber, 
ISSN-PRINT

1794-9831

E-ISSN 2322-7028

Vol. 16 No. 2

May - Ago 2019

Cúcuta, Colombia sino que está consciente de mantener controlada su enfermedad o de protegerse frente a algún otro factor de riesgo.

"Y cuando usted trata bien a la gente, se le adhieren al tratamiento, le siguen las recomendaciones, son juiciosos con las remisiones»". (Indígena ELi 28-82:52)

\section{Subcategoría 2.2.: Cómo para un Embera es dificil seguir las recomendaciones de la enfermera sobre la comida}

De manera sutil, e incluso oculta, los Embera Chamí aceptan, pero no se adaptan a las recomendaciones realizadas por las enfermeras sobre el tema relacionado con la alimentación balanceada. En este sentido, son conscientes de las bondades de la información, sin embargo, no expresan en ningún momento su incapacidad para practicar dichas recomendaciones.

También, para los indígenas Embera Chamí, es difícil dejar de comer determinados alimentos o modificar la forma de alimentarse que han mantenido históricamente. La dificultad para cambiar de hábitos alimenticios está relacionada con las limitaciones económicas y de consecución, ya sea por costumbre $\mathrm{y}$, sobre todo, por el placer que produce el consumo de determinados alimentos como la papa, el plátano, el arroz y la yuca. Esta situación perjudica directamente su estado de salud y se materializa en el aumento de peso, factor que no permite disminuir los valores de la tensión arterial y los del perfil lipídico.

"Yo les digo: «cuiden la comida». No les estoy diciendo aguanten hambre, solo le baje un poquito, y el próximo control llega pesando más, subió de peso, y los laboratorios de grasas-triglicéridos son mucho peor". (Observación participante $M G, 28-31: 05)$

Por último, se debe precisar que respecto a la alimentación balanceada recomendada por las enfermeras, no se ha logrado modificar en los indígenas, aun estando conscientes de las bondades y las posibilidades que tienen para su salud acatar estas sugerencias.

"La enfermera interviene diciendo que si consume manteca por no tener dinero para el aceite o por costumbre. La indigena dice que por costumbre". (Observación participante, 13-63:14)

\section{Discusión}

Los resultados obtenidos responden a la necesidad sentida por algunos investigadores sobre la percepción del receptor de cuidado en relación con la competencia cultural $(4,5,24,25)$. En consecuencia, se indaga sobre la importancia que tiene para los indígenas la alianza y sincronía institucional con el acto de cuidado culturalmente competente, realizado por las enfermeras de salud pública. De modo que, para los Embera Chamí este cuidado es percibido en el conjunto de acciones institucionales y profesionales asociadas con: el acceso rápido a los servicios, el apoyo económico para los tratamientos, la disminución de los tiempos de espera en la atención, la integración de los saberes tradicionales y occidentales y, sobre todo, en el cuidado basado en el respeto, la cordialidad y la cercanía.

Debe señalarse, que los resultados coinciden con algunas investigaciones que abordan la satisfacción de los pacientes en el cuidado culturalmente competente. En los estudios de Starr y Wallace (24), Castro y Ruiz (26) -sobre la percepción del cliente en relación con la competencia cultural de la enfermera- y Páez et al. (27) -realizado con médicos-, el proceso comunicativo emerge como elemento prioritario de la competencia cultural tal y como sucede en el presente estudio. Es por ello, que los receptores de cuidado identifican que: a) la enfermera generalmente tiene un lenguaje tranquilo, responde de manera clara a las preguntas, explica los resultados del examen físico; $\mathrm{y}, \mathrm{b})$ los médicos solicitan y ofrecen intercambio de información durante la visita médica; lo cual es considerado como una actitud culturalmente competente por los pacientes.

Algo semejante ocurre, con la comunicación relacionada con la satisfacción que sienten los pacientes respecto a la atención culturalmente competente. Este sentimiento también ha sido investigado en estudios cualitativos como los de Garret et al., (14) y Vogler et al.(28), quienes comprobaron que los pacientes valoran como experiencias positivas: la información, la participación, el tratamiento compasivo, amable y respetuoso, y la comunicación honesta; son características que en su mayoría coinciden con los resultados del presente estudio.

Por otra parte, la negociación y el decidir sobre las opciones de tratamiento entre el profesional y la persona que recibe el cuidado, surgen como elementos 
de la competencia cultural en estudios tanto cuantitativos como cualitativos y revisiones sistemáticas $(24,26,29,30)$; acciones que no son completamente ofrecidas por las enfermeras de éste estudio. Dicha situación está sujeta a las pocas posibilidades del indígena, a las restricciones del sistema de salud y a la visión filosófica inconsciente de la profesional; quien por otro lado, desea brindar la opción más apta y alcanzable para el indígena Embera Chamí.

Sin embargo, en la literatura científica actual relacionada con el tiempo de espera para recibir el cuidado, no se estudia como un elemento trascendental o importante. Este aspecto solo se examina en un estudio cuantitativo correlacional, cuyo objetivo era conocer el grado de competencia cultural en las enfermeras y las medidas de satisfacción en mujeres de origen latino (26). En dicho estudio, se concluyó que la reducción de los tiempos de espera produce satisfacción en estas receptoras de cuidado.

Igualmente, se afirma que existen elementos culturales como el cumplimiento en los tiempos acordados, que se convierten en un reto predecible en el cuidado culturalmente competente; por tanto su reconocimiento permite adaptar soluciones tanto a nivel institucional como profesional, de tal forma que la atención ofrecida por la enfermera sea aceptada de manera positiva y acorde a las necesidades de quienes reciben el cuidado.

Del mismo modo, algunas investigaciones han demostrado los efectos positivos del cuidado culturalmente competente con respecto a la satisfacción de los pacientes (26). Al respecto, los autores advierten que la prestación de un cuidado culturalmente competente permite el intercambio mutuo de información, la negociación, el mejoramiento de la comunicación y un mayor cumplimiento en las acciones de salud. Esta última característica está relacionada con las recomendaciones en salud ofrecidas por las enfermeras de salud pública en la IPS Intercultural, motivo de investigación en este texto, ya que es un elemento central de la subcategoría en cuestión.

Además, en una revisión sistemática (25), en la que se evaluó la eficacia de los programas culturalmente competentes en los pacientes de minorías étnicas, se demostró la validez de los modelos culturalmente competentes en términos médicos; no obstante, a pesar de que los programas pueden aumentar el co- nocimiento y la conciencia del profesional, no hay evidencia de que esto se traduzca en una mejoría en la salud del paciente. Estas conclusiones también están relacionadas con los productos planteados en la presente investigación, ya que los resultados en salud son expresados por las enfermeras y los indígenas en términos de mejora o retardo de la sintomatología de una enfermedad, la disminución de los factores de riesgo y la asistencia al control.

Como se puede advertir, los resultados ofrecen una señal de alerta respecto a los procesos educativos que se ofrecen a las enfermeras de salud pública, especialmente para quienes utilizan elementos culturalmente competentes en la atención a pacientes indígenas que estén bajo su cuidado. Por tanto, se espera de estas profesionales que se constituyan en puntos determinantes para que los indígenas Embera Chamí reciban un mayor autocuidado y con ello mejoren su salud.

En todo caso, se expone de manera explícita los largos procesos, los cambios lentos e incluso las incongruencias que las enfermeras de salud pública deben aceptar como resultado de su cuidado; sobre todo, debido a que se observa cómo las personas aun siendo conscientes de los beneficios y teniendo las posibilidades, no son capaces de cambiar determinado patrón o modificar su estilo de vida, como la alimentación balanceada.

Con respecto, a la competencia cultural, los resultados son un aporte significativo, porque permiten identificar los patrones o respuestas inconscientes o incongruentes de las personas que reciben el cuidado. Dichos comportamientos se deben tener en cuenta por parte de las enfermeras, ya que forman parte de la cultura de las personas a las que cuidan y por tanto, contribuir al mejoramiento y materialización de la competencia cultural.

De igual manera, los procesos conscientes o inconscientes que producen acciones incongruentes en las personas receptoras de cuidado, no han sido objeto de estudio por parte de la literatura relacionada con la competencia cultural. Por tanto, los resultados de esta investigación servirán de evidencia respecto de algunas acciones que se realizan pero que no generan ninguna repercusión en los resultados de salud de una persona, por lo que se hace un llamado a replantear algunas formas de cuidado que pueden llegar a ser infructuosas. Así mismo, se invita a tratar de entender 
ISSN-PRINT

1794-9831

E-ISSN 2322-7028

Vol. 16 No. 2

May - Ago 2019

Cúcuta, Colombia que las personas tienen procesos mentales conscientes o inconscientes que no son del todo coherentes y que por tanto deben estar bajo la mirada de un cuidado culturalmente competente en salud pública.

En general, los resultados de ésta investigación proporcionan de forma teórica elementos que mejoran la práctica del cuidado culturalmente competente como la empatía y la adaptación a las creencias de los Embera; en este sentido se percibe: satisfacción, mayor adherencia al tratamiento farmacológico, aumento en las prácticas de autocuidado y menor inasistencia a los controles por parte de la persona que recibe los cuidados.

\section{Conclusiones}

- El análisis de los resultados permite vislumbrar la satisfacción de los indígenas con las enfermeras $\mathrm{y}$, de manera conjunta, con la IPS intercultural, cuando el cuidado se realiza con base en el respeto, la formalidad, el suficiente tiempo para el cuidado, la explicación detallada y la valoración completa. Todo ello relacionado, además, con un contexto institucional que ofrece un acceso oportuno de las citas, atención oportuna, acercamiento de la institución a las comunidades, apoyo en transporte, estadía, alimentación e integración de la medicina occidental y tradicional

- La percepción del Embera, además de expresarse en la satisfacción se aprecia en los resultados en salud. Para los indígenas, el control realizado por las enfermeras cobra importancia para su vida, por lo que intentan seguir las recomendaciones ofrecidas por las profesionales, especialmente en lo relacionado a la adherencia a los medicamentos, aumento del autocuidado y mayor asistencia a los controles. Lo anterior influye de manera positiva en el estado de salud de los indígenas, retardando las complicaciones de algunas patologías o disminuyendo los factores de riesgo.

- Pese a los aspectos con los que el cuidado culturalmente competente puede influir de manera positiva en la salud de los indígenas, los asuntos relacionados con la alimentación balanceada son difíciles de cumplir para este grupo poblacional, situación novedosa al no reportarse de manera explícita en la literatura científica, convirtiéndose en un reto para la práctica y la investigación sobre cuidados culturales con población indígena.

- Como elemento de importancia en la percepción del indígena Embera Chamí, frente al cuidado recibido, se encuentra además la molestia con el tiempo de espera para ser atendido, cuyo reclamo ha estado presente desde tiempo atrás con otras instituciones y que en algunos casos persiste en la actualidad.

- La competencia cultural es un proceso que se materializa en el profesional; sin embargo, con esta investigación se demuestra que hay una relación directa con la percepción del receptor de cuidado, por lo que se hace necesario indagar acerca de cómo son los procesos de adaptación de quienes lo reciben. Así mismo, resultará importante investigar cómo interviene la adaptación en el acto de cuidado y en los resultados en salud que cambian la cultura de las personas.

\section{Referencias bibliográficas}

1. McFarland MR, Wehbe Alamah HB. Leininger's Culture Care Diversity and Universality a Worldwide Nursing Theory. 3ra ed. Burlington, MA: Jones \& Bartlett Learning; 2015. 1-612 p.

2. Campinha Bacote J. El Proceso de Competencia Cultural en la prestación de Servicios de Salud [Internet]. 2012 [citado el 14 de julio de 2018]. Disponible en: http://transculturalcare.net/the-process-ofcultural-competence-in-the-delivery-of-healthcare-services/

3. Purnell L. The Purnell Model for Cultural Competence. J Transcult Nurs [Internet]. 2002 [citado el 14 de julio de 2018];13(3):193-6. Disponible en: https://www.ncbi.nlm.nih.gov/pubmed/12113149

4. Loftin C, Hartin V, Branson M, Reyes H. Measures of Cultural Competence in Nurses: An Integrative Review. ScientificWorldJournal [Internet]. 2013 [citado el 9 de junio de 2018];2013. Disponible en: http://www.pubmedcentral.nih.gov/articlerender.fcgi?artid=3683494\&tool=pmcentrez\&rendertype $=\mathrm{a}$ $\underline{\text { bstract }}$ 
5. Swanson CR. The Case for Studying Cultural Competence from the Perspective of the Hispanic Immigrant Patient: A State of the Science. Online J Cult Competence Nurs Heal [Internet]. 2012 [citado el 9 de junio de 2018];2(1):1-9. Disponible en: www.ojccnh.org/pdf/v2n1a1.pdf

6. Lie DA, Lee Rey E, Gomez A, Bereknyei S, Braddock C. Does cultural competency training of health professionals improve patient outcomes? A systematic review and proposed algorithm for future research. J Gen Intern Med [Internet]. 2011 [citado el 9 de junio de 2018];26(3):317-25. Disponible en: http://www.pubmedcentral.nih.gov/articlerender.fcgi?artid=3043186\&tool=pmcentrez\&rendertype $=\mathrm{abs}$ $\underline{\text { tract }}$

7. Robinson N, Lorenc A. Traditional and complementary approaches to child health. Nurs Stand [Internet]. 2011 [citado el 9 de junio de 2018];25(38):39-47. Disponible en: http://www.ncbi.nlm.nih.gov/ pubmed/21706977

8. Pelcastre Villafuerte B, Ruiz M, Meneses S, Amaya C, Márquez M, Taboada A, et al. Communitybased health care for indigenous women in Mexico: a qualitative evaluation. Int J Equity Heal [Internet]. 2014 [citado el 9 de junio de 2018];13. Disponible en: https://www.ncbi.nlm.nih.gov/pmc/ articles/PMC3893537/?tool=pmcentrez\&report=abstract

9. McGinnis SL, Brush BL, Moore J. Cultural similarity, cultural competence, and nurse workforce diversity. West J Nurs Res [Internet]. 2010 [citado el 14 de julio de 2018];32(7):894-909. Disponible en: https://www.ncbi.nlm.nih.gov/pubmed/20634397

10. OIT. Oficina Internacional del Trabajo. Manual para los mandantes tripartitos de la OIT. Comprender el convenio sobre pueblos indígenas y tribales, 1989 (núm.169) [Internet]. Vasa. 2013 [citado el 14 de julio de 2018]. p. 60. Disponible en: http://www.ilo.org/global/standards/subjects-covered-by-international-labour-standards/indigenous-and-tribal-peoples/WCMS 205230/lang--es/index.htm

11. Aseltine RH, Katz MC, Holmes C. Providing medical care to diverse populations: findings from a follow-up survey of Connecticut physicians. Conn Med [Internet]. 2011 [citado el 14 de julio de 2018];75(6):337-44. Disponible en: https://www.ncbi.nlm.nih.gov/pubmed/21755849

12. Serra Galceran M, Mestres Camps L, Gonzáles Soriano M, Leiva Moral JM, De Dios Sanchez R, Montiel Pastor M. Competencia clínico cultural: Análisis de la capacitación de los profesionales de la salud. Index de Enfermería. 2013;22(1-2):16-9.

13. Starr S, Wallace DC. Self-reported cultural competence of public health nurses in a Southeastern U.S. Public health department. Public Heal Nurs [Internet]. 2009 [citado el 9 de junio de 2018];26(1):4857. Disponible en: http://www.ncbi.nlm.nih.gov/pubmed/19154192

14. Garrett PW, Dickson HG, Whelan AK, Roberto-Forero. What do non-English-speaking patients value in acute care? Cultural competency from the patient's perspective: a qualitative study. Ethn Health [Internet]. 2008 [citado el 14 de julio de 2018];13(5):479-96. Disponible en: https://www.ncbi.nlm. nih.gov/pubmed/18850371

15. Archibald C. Cultural Tailoring for an Afro-Caribbean Community: A Naturalistic Approach. Cult Divers. 2011;18(4):114-9.

16. Ariza Montoya J, Hernández Álvarez M. Equidad de etnia en el acceso a los servicios de salud en Bogotá, Colombia, 2007. Rev salud pública. 2008;10(1):58-71.

17. Gobernación de Caldas. Curso: Etnoeducación comunidad indígena de Caldas. 2013. 1-55 p.

18. Alcaldía Municipal de Riosucio. Información del municipio [Internet]. 2015 [citado el 14 de julio de 2018]. Disponible en: http://www.riosucio-caldas.gov.co/MiMunicipio/Paginas/Informacion-delMunicipio.aspx

19. Guber R. La etnografía: método, campo y reflexividad. Bogotá D.C: Grupo Editorial Norma; 2007. $140 \mathrm{p}$.

20. Geertz C. La interpretación de las culturas. Barcelona: Gedisa; 1998. 1-568 p. 
ISSN-PRINT

1794-9831

E-ISSN 2322-7028

Vol. 16 No. 2

May - Ago 2019

Cúcuta, Colombia

21. Rodríguez VG, Vera G, Vargas AM. Etnografía: una mirada desde corpus teórico de la investigación cualitativa. Omnia [Internet]. 2011 [citado el 14 de julio de 2018];17(2):26-39. Disponible en: http:// www.redalyc.org/articulo.oa?id $=73719138003$

22. Martínez Miguélez M. Ciencia y arte en la metodología cualitativa. México D.F.: Editorial Trillas; 2004. 1-351 p.

23. Critical Appraisal Skills Programme Español. Entendiendo la evidencia de estudios cualitativos [Internet]. 10 preguntas para ayudarte a entender un estudio cualitativo. 2016 [citado el 14 de julio de 2018]. p. 1-6. Disponible en: http://www.redcaspe.org/herramientas/instrumentos

24. Starr S, Wallace DC. Client perceptions of cultural competence of community-based nurses. J Community Heal Nurs [Internet]. 2011 [citado el 9 de junio de 2018];28(2):57-69. Disponible en: https:// www.ncbi.nlm.nih.gov/pubmed/21541868

25. Renzaho AM, Romios P, Crock C, Sønderlund AL. The effectiveness of cultural competence programs in ethnic minority patient-centered health care--a systematic review of the literature. Int J Qual Heal Care [Internet]. 2013 [citado el 9 de junio de 2018];25(3):261-9. Disponible en: https:/www.ncbi. nlm.nih.gov/pubmed/23343990

26. Castro A, Ruiz E. The effects of nurse practitioner cultural competence on Latina patient satisfaction. J Am Acad Nurse Pr [Internet]. 2009 [citado el 9 de junio de 2018];21(5):278-86. Disponible en: https://www.ncbi.nlm.nih.gov/pubmed/19432912

27. Paez KA, Allen JK, Beach MC, Carson K a, Cooper L a. Physician cultural competence and patient ratings of the patient-physician relationship. J Gen Intern Med [Internet]. 2009 [citado el 14 de julio de 2018];24(4):495-8. Disponible en: https://www.ncbi.nlm.nih.gov/pmc/articles/PMC2659158/?too $1=$ pmcentrez\&report $=$ abstract

28. Vogler J, Altman TK, Zoucha R. Native Hawaiian attitudes of culturally sensitive healthcare provider traits and behaviors. J Cult Divers [Internet]. 2010 [citado el 9 de junio de 2018];17(3):90-8. Disponible en: https://www.ncbi.nlm.nih.gov/pubmed/20860333

29. Cioffi J. Culturaly diverse family members and their hospitalised relatives in acute care wards: a qualitative study. Aust J Adv Nurs [Internet]. 2006 [citado el 14 de julio de 2018];24(1):15-20. Disponible en: https://www.ncbi.nlm.nih.gov/pubmed/17019820

30. Ngo Metzger Q, Telfair J, Sorkin DH, Weidmer B, Weech Maldonado R, Hurtado M, et al. Cultural competency and quality of care: Obtaining the patient's perspective [Internet]. The Commonwealth Fund. 2006 [citado el 14 de julio de 2018]. Disponible en: http://www.commonwealthfund.org/publications/fund-reports/2006/oct/cultural-competency-and-quality-care-obtaining-patients 